\title{
A survey of 25 years' transpolar voltage data from the SuperDARN radar network and the Expanding-Contracting Polar Cap model
}

\section{Article}

Published Version

Creative Commons: Attribution 4.0 (CC-BY)

Open Access

Lockwood, M. ORCID: https://orcid.org/0000-0002-7397-2172 and McWilliams, K. A. (2021) A survey of 25 years' transpolar voltage data from the SuperDARN radar network and the Expanding-Contracting Polar Cap model. Journal of Geophysical Research: Space Physics, 126 (9). e2021JA029554. ISSN 2169-9402 doi: https://doi.org/10.1029/2021JA029554 Available at https://centaur.reading.ac.uk/99508/

It is advisable to refer to the publisher's version if you intend to cite from the work. See Guidance on citing.

To link to this article DOI: http://dx.doi.org/10.1029/2021JA029554

Publisher: American Geophysical Union

All outputs in CentAUR are protected by Intellectual Property Rights law, including copyright law. Copyright and IPR is retained by the creators or other copyright holders. Terms and conditions for use of this material are defined in the End User Agreement. 


\section{www.reading.ac.uk/centaur}

\section{CentAUR}

Central Archive at the University of Reading

Reading's research outputs online 


\section{JGR Space Physics}

\section{RESEARCH ARTICLE \\ 10.1029/2021JA029554 \\ Key Points: \\ - Transpolar voltage depends on both dayside and nightside reconnection voltages and both are enhanced by larger solar wind dynamic pressure \\ - Large voltages seen when the interplanetary magnetic field (IMF) points northward decay away with elapsed time since the IMF last pointed southward \\ - Ongoing nightside reconnection mimics the effect of proposed viscous-like interactions which are shown to cause considerably less than $15 \mathrm{kV}$ of voltage}

Correspondence to:

M. Lockwood,

m.lockwood@reading.ac.uk

Citation:

Lockwood, M., \& McWilliams, K. A. (2021). A survey of 25 years' transpolar voltage data from the SuperDARN radar network and the expandingcontracting polar cap model. Journal of Geophysical Research: Space Physics, 126, e2021JA029554. https://doi. org/10.1029/2021JA029554

Received 11 MAY 2021 Accepted 26 JUL 2021 (c) 2021. The Authors.

This is an open access article under the terms of the Creative Commons Attribution License, which permits use, distribution and reproduction in any medium, provided the original work is properly cited.

\section{A Survey of 25 Years' Transpolar Voltage Data From the SuperDARN Radar Network and the Expanding- Contracting Polar Cap Model}

\author{
Mike Lockwood $^{1}$ (i) and Kathryn A. McWilliams ${ }^{2}$ (i) \\ ${ }^{1}$ Department of Meteorology, University of Reading, Reading, UK, ${ }^{2}$ Institute of Space and Atmospheric Studies, \\ University of Saskatchewan, Saskatoon, SK, Canada
}

\begin{abstract}
We use 214,410 hourly observations of transpolar voltage, $\Phi_{\mathrm{PC}}$, from 25 years' observations by the Super Dual Auroral Radar Network radars to confirm the central tenet of the expandingcontracting polar cap model of ionospheric convection that $\Phi_{\mathrm{PC}}$ responds to both dayside and nightside reconnection voltages $\left(\Phi_{\mathrm{D}}\right.$ and $\left.\Phi_{\mathrm{N}}\right)$. We show that $\Phi_{\mathrm{PC}}$ not only increases at a fixed level of the nightside auroral electrojet $A L$ index with increasingly southward interplanetary magnetic field (IMF) (identifying the well-known effect of $\Phi_{\mathrm{D}}$ on $\Phi_{\mathrm{PC}}$ ) but also with increasingly negative $A L$ at a fixed southward IMF (identifying a distinct effect of $\Phi_{\mathrm{N}}$ on $\Phi_{\mathrm{PC}}$ ). We also study the variation of $\Phi_{\mathrm{PC}}$ with time elapsed since the IMF last pointed southward, $\Delta t$, and show that low/large values occur when $(-A L)$ is small/large. Lower numbers of radar echoes, $n_{\mathrm{e}}$, mean that the "map-potential" reanalysis technique used to derive $\Phi_{\mathrm{PC}}$ is influenced by the model used: we present a sensitivity study of the effect of the threshold of $n_{\mathrm{e}}$ required to avoid this. We show that for any threshold $n_{e}, \Phi_{\mathrm{PC}}$ falls to about $15 \mathrm{kV}$ for $\Delta t$ greater than about $15 \mathrm{~h}$, indicating any viscous-like voltage $\Phi_{\mathrm{V}}$ is considerably smaller than this. It is shown that both $\Phi_{\mathrm{PC}}$ and $(-A L)$ increase with increased solar wind dynamic pressure $p_{\mathrm{Sw}}$, but not as much as the midlatitude geomagnetic index $a m$. We conclude $p_{\mathrm{Sw}}$ increases both $\Phi_{\mathrm{D}}$ and $\Phi_{\mathrm{N}}$ through increasing the magnetic shear across the relevant current sheet but has a larger effect on midlatitude geomagnetic indices because of the effect of additional energy stored in the tail lobes.
\end{abstract}

Plain Language Summary Large-scale circulation of the ionized upper atmosphere over the poles is driven by the solar wind flow by the process of magnetic reconnection that interconnects the magnetic field of Earth with that embedded in the solar wind flow. In long-term averages, the rate at which this "open" magnetic flux is transferred away from the Sun and in the polar ionospheres is the same, but on shorter timescales the field can stretch between the two locations and this decouples the transfer rates. The expanding-contracting polar cap model has been very useful in predicting the faster changes that can occur in the ionosphere, changes that can have an influence on a wide range of modern operational systems from satellites to power grids. Two key concepts that the model is based on were obtained from only very small data sets and here we use 214,410 hourly observations from 25 years of observations by the Super Dual Auroral Radar Network to show that the concepts do apply all the time.

\section{Introduction}

This paper studies the expanding-contracting polar cap (ECPC) model of ionospheric convection excitation (Cowley \& Lockwood, 1992) using an unprecedentedly large data set of observations of the transpolar voltage $\Phi_{\mathrm{PC}}$, also known as the cross-cap potential difference. The ECPC model predicts that $\Phi_{\mathrm{PC}}$ at any one instant depends on the reconnection voltage in the cross-tail current sheet $\Phi_{\mathrm{N}}$ as well as that at the dayside magnetopause $\Phi_{\mathrm{D}}$.

One specific aim is to recreate two scatter plots from surveys of $\Phi_{\mathrm{PC}}$ that have been of great importance to our understanding of the excitation of ionospheric polar convection by the solar wind flow, but here using a much larger data set of observations. The first of these scatter plots shows the dependence of $\Phi_{\mathrm{PC}}$ on the northward component $B_{Z}$ of the interplanetary magnetic field (IMF) in the geocentric solar magnetospheric (GSM) reference frame (Boyle et al., 1997; Cowley, 1984; Hairston et al., 1998; Liu et al., 2019; Milan, 2004; Reiff et al., 1981). The second scatter plot shows the dependence of $\Phi_{\mathrm{PC}}$ during northward $\operatorname{IMF}\left(B_{Z}>0\right)$ on 
the time elapsed since the IMF was last southward (Wygant et al., 1983). We also aim to use the large data set, which covers more than a whole Hale solar magnetic cycle, to extend our understanding of the separate effects of reconnection in the magnetopause and the cross-tail current sheet by comparisons with the behavior of the $A L$ auroral electrojet index (Davis \& Sugiura, 1966), and to investigate the separate effects of solar wind dynamic pressure on $\Phi_{\mathrm{D}}$ and $\Phi_{\mathrm{N}}$.

\subsection{Transpolar Voltage, Steady State, and Non-Steady-State Convection}

Magnetospheric convection (the circulation of plasma and frozen-in magnetic field) is at the heart of our understanding of the response of geomagnetic activity and terrestrial space weather to the transfer of energy from the solar wind into the magnetosphere. Directly driven geomagnetic responses, historically called "Disturbance Polar-2" or "DP-2," are usually dominated by eastward currents in the afternoon sector polar auroral ionosphere and detected as positive enhancements of the $A U$ auroral electrojet index (Davis \& Sugiura, 1966). DP-2 currents correlate highly with solar wind forcing at short response delays (Etemadi et al., 1988; Lockwood et al., 1986; Nishida, 1968a, 1968b; Todd et al., 1988). These are driven responses to magnetic reconnection in the dayside magnetopause current sheet, which generates open magnetospheric field lines (Consolini \& De Michelis, 2005; Echer et al., 2017; Finch et al., 2008), the voltage $\Phi_{\mathrm{D}}$ being the magnetic flux transfer rate from the closed to open magnetospheric field-line topology. The open field lines generated are swept into the geomagnetic tail by the solar wind flow where they accumulate, storing energy there. These open field lines in the tail are subsequently reclosed in bursts of reconnection in the cross-tail current sheet, giving the storage-release responses of geomagnetic activity ("DP-1") after a longer lag time than for the DP-2 response (Baker et al., 1983; Finch et al., 2008; Klimas et al., 1992, 1994; McPherron et al., 1998). The DP-1 response is dominated by the effects of the westward auroral electrojet current across midnight in the substorm current wedge and seen as negative perturbations of the $A L$ auroral electrojet index (Davis \& Sugiura, 1966). The voltage $\Phi_{\mathrm{N}}$ is the magnetic flux transfer rate from the open to the closed magnetospheric field-line topology. The storage-release response is often described in terms of the magnetospheric substorm cycle (e.g., Baker et al., 1997; McPherron et al., 1998). A review of the development of our understanding of the relationship of magnetospheric flux transport, the Dungey convection cycle, and substorms has been given by McPherron (2020) and a review of the associated energy flow through the magnetosphere has been given by Lockwood (2019).

Being at the foot of magnetospheric field lines and, like the magnetosphere, being of high magnetic Reynolds number, the frozen-in flux theorem applies to the polar ionospheric F-region and topside ionosphere. Hence, these regions reflect the circulation of frozen-in flux in the magnetosphere (ionospheric convection). However, there is one key difference between the flows in the magnetosphere and in the ionosphere. The magnetosphere is compressible, a fact that the storage-release system depends upon. On the other hand, the ionosphere is incompressible, in the sense that the magnetic field there is constant to within a very small factor, such that even a very large geomagnetic disturbance is only a very small fraction of the intrinsic geomagnetic field (for example, 1,000 nT is less than a $2 \%$ perturbation). The reason for this is the ionosphere's close proximity to the currents in the Earth's interior that generate the geomagnetic field. This difference means that during substorm growth phases, when energy is accumulating in the near-Earth lobes of the magnetospheric geomagnetic tail because the field there is growing (and to some extent also because the lobes are expanding in cross-sectional area as the tail flares), the ionospheric footprint of the open field lines in the lobes (the open polar caps) must be expanding in area (Holzer et al., 1986; Huang et al., 2009; Lockwood \& Cowley, 1992; Lockwood et al., 1990; Milan et al., 2003, 2009, 2012). Siscoe and Huang (1985) showed how expanding "adiaroic" segments of the polar cap boundaries (meaning "not flowing across," i.e., not mapping to a magnetospheric reconnection site) would influence the pattern of ionospheric convection. This concept was used by Cowley and Lockwood (1992) to show how ionospheric convection is driven by both the generation and destruction of open flux (the ECPC model). This is different to the magnetosphere, where flows are driven by the solar wind flow, pressure balance, and the magnetohydrodynamic (MHD) curvature force that acts to straighten bent field lines. The ECPC concept is supported by detailed comparisons between theory and observations of how patches of newly opened flux, generated by magnetopause reconnection bursts, evolve poleward (Cowley, Freeman, et al., 1991; Lockwood et al., 1993, 2006; McWilliams et al., 2000; Throp et al., 2005). The result of these considerations is that ionospheric convection is not, in general, a straightforward image of the magnetospheric circulation and the two are decoupled by 
induction effects-changes in the magnetic field between the magnetosphere and the ionosphere which, by Faraday's law, give a curl in the electric field (Lockwood \& Cowley, 1992; Lockwood \& Morley, 2004; Lockwood et al., 1990). In steady state, the electric field becomes curl-free and electrostatic potentials do map down magnetic field lines. In addition, in steady state the adiaroic boundaries are not moving. Steady state applies when data are averaged over a long enough timescale; however, theory of substorm growth and expansion predicts that it will not apply to the timescales of a few substorm cycles or less. That is not to say that balanced reconnection events, when dayside and nightside reconnection voltages are approximately equal, do not occur (DeJong et al., 2008; Lockwood et al., 2009): these can occur by chance but, probably more often, they occur because changes in the dayside reconnection voltage are sufficiently slow, such that it is never greatly different to the lagged nightside voltage response (Milan et al., 2021). Surveys by Lockwood et al. (2009) and Milan et al. (2021) have looked at the relative occurrence of substorm cycles and quasi-balanced reconnection. Note that the ECPC model is the general case as it can predict quasi-steady, quasi-balanced reconnection (if the interplanetary conditions driving dayside reconnection vary slowly enough) as well substorm cycles. On the other hand, balanced reconnection is not the general case as it cannot predict substorm cycles (nor is there any known mechanism that can act to balance the reconnection rates at any one instant). Lockwood (1991) pointed out that the motion of adiaroic convection reversals boundaries means that they are smoothed out in average patterns of convection. On timescales shorter than the substorm cycle of polar cap expansion and contraction, ionospheric convection reflects both the DP-2 and DP-1 current systems and displays the response delays associated with both (respectively a few minutes and 30-60 min). In addition, because of a combination of ionospheric incompressibility and the antisunward motion of open field lines, the direct response delay to IMF changes varies with location, increasing with distance away from noon (Lockwood et al., 1986; Lopez et al., 1999; Morley \& Lockwood, 2005; Saunders et al., 1992).

Convection is often quantified by the transpolar voltage $\Phi_{\mathrm{PC}}$ between convection reversal boundaries (CRBs) in the ionosphere on the dawnside and the duskside of the polar cap (Boyle et al., 1997; Cowley, 1984; Hairston et al., 1998; Liu et al., 2019; Reiff et al., 1981). This parameter is measured by a spacecraft in high-inclination, low-earth orbit (LEO) by integration of the observed "along-track" component of the electric field along the satellite path between the two dominant CRBs. That electric field can either be directly measured or derived from observations of the vector magnetic field, $\vec{B}$ and the plasma flow $\vec{V}$ and using the equation of ideal MHD $\vec{E}=-\vec{V} \times \vec{B}$ which applies to a very high degree of accuracy even in the F-region ionosphere because of the high magnetic Reynold's number (Hanson et al., 1993). Hence, by integrating the along-track electric field (corresponding to the cross-track drift) between the two main CRBs, the transpolar voltage $\Phi_{\mathrm{PC}}$ is measured for that satellite path. The quantity $\Phi_{\mathrm{PC}}$ is often accurately called the "polar cap potential drop," but also frequently (but inaccurately) referred to as the "cross-cap potential" or "polar cap potential." Strictly speaking, it is a potential difference, that is, a voltage and this semantic point has real physical significance to understanding because, by Faraday's induction law, a voltage is synonymous with magnetic flux transfer rate whereas a potential is not. Hence, we here use the term "transpolar voltage" for $\Phi_{\mathrm{PC}}$ and note that it is the rate at which magnetic flux is transferred across the polar cap. One convention that can be used is that positive transpolar voltage means that the dawnside CRB potential exceeds the duskside CRB potential (i.e., the electric field is from dawn to dusk), and this applies most of the time because net flux transfer is from the dayside to nightside. The reason for this is that open flux is, by definition, embedded in the solar wind flow and the solar wind is always transferring that open flux antisunward, and even during the longest intervals of northward IMF, the open flux never decays away completely. This antisunward flux transport remains dominant during northward IMF despite interruptions by intervals of sunward flow of some open flux tubes caused by them being reconfigured by lobe reconnection taking place at the magnetopause at the sunward edge of the tail lobes (see review by Lockwood \& Moen, 1999). In terms of magnetospheric configuration and voltages, this means the geomagnetic tail is always present and so magnetic shear is always present between the two tail lobes giving some level of magnetic reconnection in the associated cross-tail current sheet. In addition, reconnection at the low-latitude dayside magnetopause (i.e., between the magnetic cusps) that opens geomagnetic field lines has been observed to continue (at a low level) during intervals of northward IMF (Chandler et al., 1999; Fuselier et al., 2000).

Figure 1 is a schematic of the three drivers of convection in the magnetosphere and ionosphere during southward IMF. This is adapted from Cowley (1982), but with the addition of a reconnection X-line in 


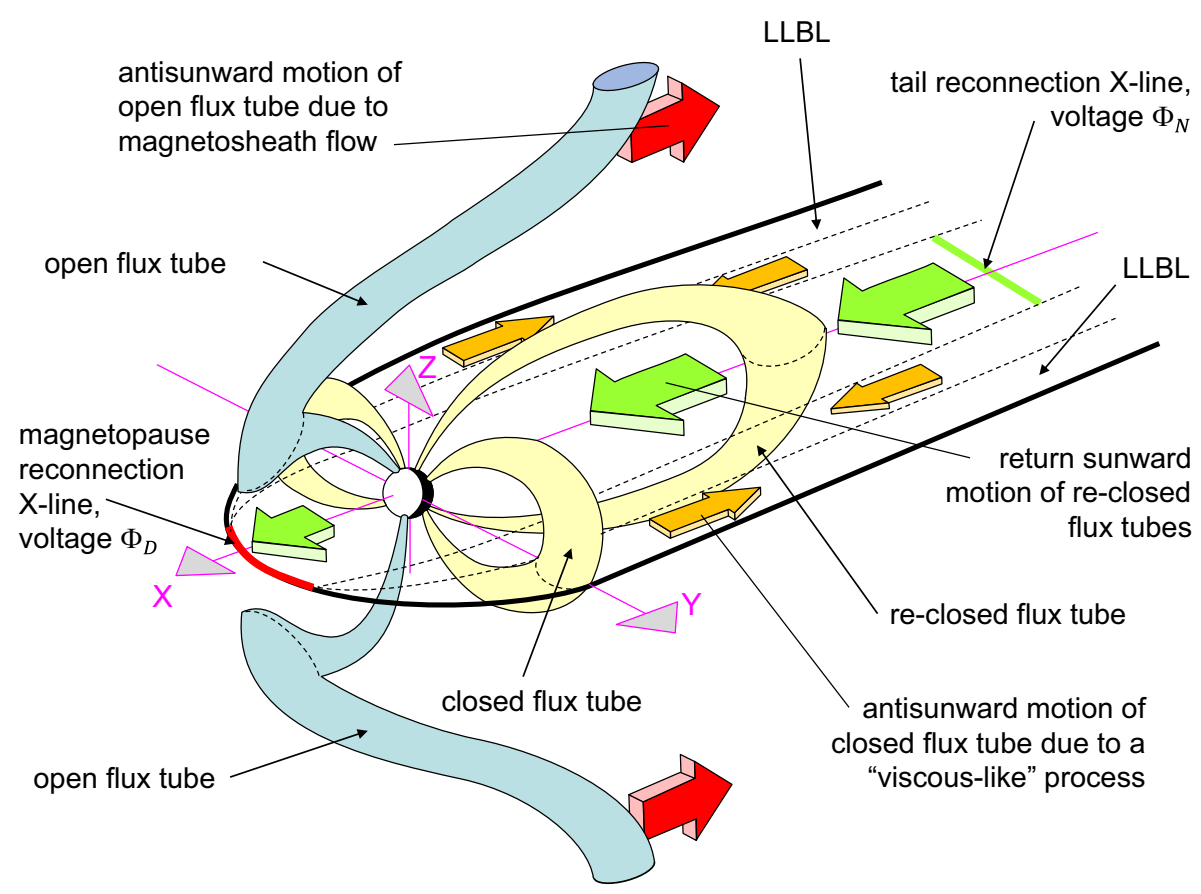

Figure 1. Schematic of three convection drivers in the magnetosphere and ionosphere, adapted from Cowley (1982) with the addition of a reconnection X-line in the cross-tail current sheet (in green, the voltage across which is $\Phi_{\mathrm{N}}$ ). This X-line recloses open field lines and is included here because in the expanding-contracting polar cap model (Cowley \& Lockwood, 1992), it contributes to the ionospheric transpolar voltage $\Phi_{\mathrm{PC}}$ at any one time by adding to the effect of the reconnection voltage $\Phi_{\mathrm{D}}$ along the dayside magnetopause X-line (in red), which generates open field lines. The third source of $\Phi_{\mathrm{PC}}$ is "viscous-like" momentum transfer across the magnetopause onto closed field lines that generates a total antisunward magnetic flux transfer of closed flux of voltage $\Phi_{\mathrm{V}}$ in the low latitude boundary layers (LLBL).

the cross-tail current sheet (in green, the voltage across which is $\Phi_{\mathrm{N}}$ ) that recloses open field lines. This is included here because in the ECPC model (Cowley \& Lockwood, 1992) it contributes to the ionospheric transpolar voltage $\Phi_{\mathrm{PC}}$. The ECPC model predicts that at any one time, the effect of $\Phi_{\mathrm{N}}$ combines with the effect of the reconnection voltage $\Phi_{\mathrm{D}}$ along the dayside magnetopause reconnection X-line (in red) which generates open field lines. The third source of $\Phi_{\mathrm{PC}}$ illustrated here is "viscous-like" momentum transfer across the magnetopause onto closed field lines that generates a total antisunward magnetic flux transfer of closed flux of voltage $\Phi_{\mathrm{V}}$ in the low-latitude boundary layers (LLBL) on the dawn and dusk flanks of the magnetosphere. Figure 2 is a schematic of ionospheric flow patterns that is compatible with Figure 1 and the ECPC model in general. Figure 2a shows the special case of steady state $\left(\Phi_{\mathrm{D}}=\Phi_{\mathrm{N}}\right)$ with some viscous-like flow cells $\left(\Phi_{\mathrm{V}}>0\right)$ and is as in the schematic used by Cowley (1982). Figures $2 \mathrm{~b}$ and $2 \mathrm{c}$ are examples of ECPC model predictions for an expanding and a contracting polar cap, respectively. For polar cap expansion, $\Phi_{\mathrm{D}}>\Phi_{\mathrm{N}}$ and $\Phi_{\mathrm{PC}} \approx \Phi_{\mathrm{D}}$. For a contracting polar cap, $\Phi_{\mathrm{N}}>\Phi_{\mathrm{D}}$ and $\Phi_{\mathrm{PC}} \approx \Phi_{\mathrm{N}}$. In Figures $2 \mathrm{~b}$ and $2 \mathrm{c}$, no viscous flow excitation is included $\left(\Phi_{\mathrm{V}}=0\right)$, but several features often mistaken for viscous-like flows are still seen in Figure 2c. In particular, the convection pattern shows flow streamlines entering the polar cap over the entire dayside and the transpolar voltage exceeds the dayside reconnection voltage $\left(\Phi_{\mathrm{PC}} \approx \Phi_{\mathrm{N}}>\Phi_{\mathrm{D}}\right)$.

The presence of lobe stirring cells during northward IMF, or lobe field line reclosure by reconnection at the sunward edges of both the lobes (e.g., Lockwood \& Moen, 1999), means that northward IMF is inherently a non-steady-state situation because, by Faraday's law, the electric field has a curl with dawn-to-dusk electric field associated with reconnection in the cross-tail current sheet but dusk-to-dawn electric field along the lobe reconnection site(s) at the sunward edge(s) of the lobe magnetopause (Lockwood, 2019). Hence, during the 50\% of time that the IMF points northward (Hapgood et al., 1991; Lockwood et al., 2017, 2019b) the magnetosphere is generally quiet but also inherently in a non-steady state because of the slow decay of open flux (see review by Lockwood, 2019). 

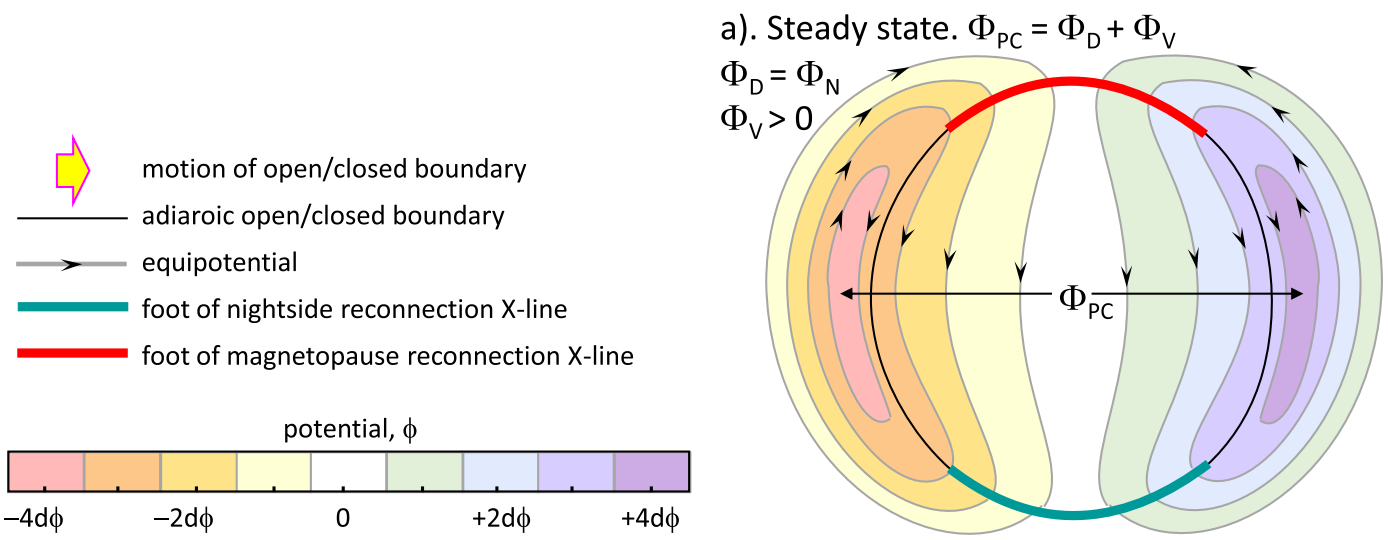

b). Expanding polar cap.

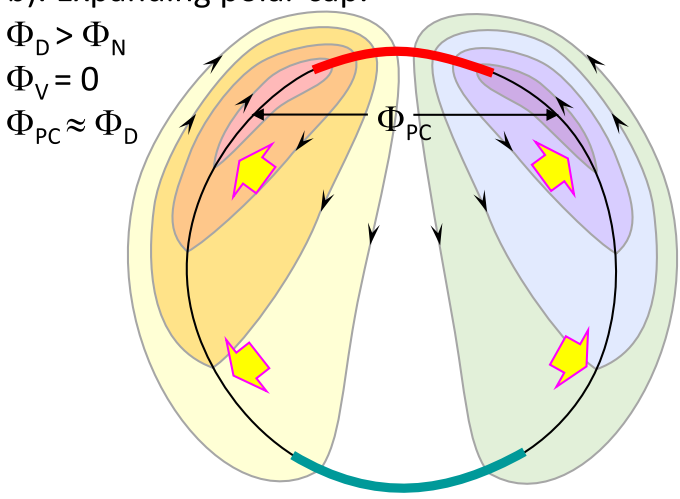

c). Contracting polar cap.

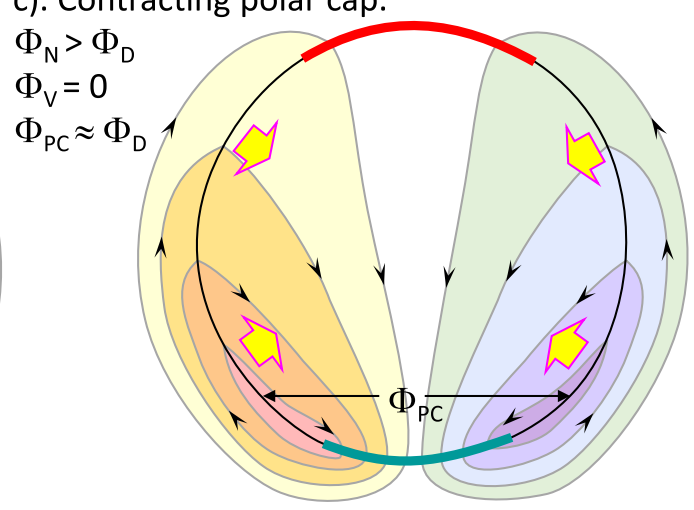

Figure 2. Schematic illustration of northern hemisphere ionospheric flow streamlines (equipotentials, $d \phi$ apart) under the influence of three driving voltages $\Phi_{\mathrm{D}}, \Phi_{\mathrm{N}}$, and $\Phi_{\mathrm{V}}$ discussed in Figure 1, as predicted by the expanding-contracting polar cap model of ionospheric flow excitation for the special case where polar cap remains circular: (a) is for steady state (also known as balanced reconnection), (b) for an expanding polar cap, and (c) for a contracting polar cap. Yellow arrows give the motion of the non-reconnecting, "adiaroic" open-closed boundary segments which are shown in black.

Figure 3 gives two schematics of a northern hemisphere convection pattern that we would expect during northward IMF; specifically, if the IMF has (a) components $B_{Z}>0$ and $B_{Y}=0$ and, (b) $B_{Z}>0$ and $B_{Y}>0$ in the GSM reference frame. Figure 3a shows the case of lobe reconnection (voltage $\Phi_{\mathrm{L}}$ ) driving symmetric lobe circulation cells in the open polar cap, as well as the effects of reconnection voltages $\Phi_{\mathrm{D}}$ and $\Phi_{\mathrm{N}}$ and a viscous-like voltage $\Phi_{\mathrm{V}}$. In Figure 3b, the magnetic curvature force on newly reconfigured open field lines for the large positive IMF $B_{Y}$ causes the dawn lobe cell to dominate: note in this case how the poleward contraction of the (dusk) adiaroic open polar cap boundary causes the sunward flowing portion at lower potentials of this one lobe convection cell to merge with the main dusk cell.

Because here we survey a very large data set, we need to automate the scaling of transpolar voltage and we found that automated algorithms to distinguish and identify lobe cells from the cells driven by $\Phi_{\mathrm{D}}, \Phi_{\mathrm{N}}$, and $\Phi_{\mathrm{V}}$ were not reliable, particularly given that the merging of lobe and main flow cells illustrated in Figure $3 \mathrm{~b}$ is often seen for northward IMF conditions. To enable automated scaling, here we define $\Phi_{\mathrm{PC}}$ by

$$
\Phi_{\mathrm{PC}}=\phi_{\max }-\phi_{\min }
$$

We apply this, irrespective of the locations at which the maximum $\left(\phi_{\max }\right)$ and minimum $\left(\phi_{\min }\right)$ of the potential pattern occurs. This is good for investigating the ECPC model because it allows for the sunward and antisunward shifts of the locations of both $\phi_{\max }$ and $\phi_{\min }$ caused by dominant $\Phi_{\mathrm{D}}$ and $\Phi_{\mathrm{N}}$, respectively (see Figures $2 \mathrm{~b}$ and $2 \mathrm{c}$ ). The maximum potential $\phi_{\max }$ is usually the potential at the center of the main convention cell on the dawn flank of the polar cap ( $\phi_{\text {dawn } 1}$ in Figure 3$)$ and the $\phi_{\min }$ is usually the potential at the center of the main cell on the dusk flank of the polar cap ( $\phi_{\text {dusk } 1}$ in Figure 3$)$. However, if the lobe reconnection voltage $\Phi_{\mathrm{L}}$ is large enough, $\phi_{\max }$ can become $\phi_{\text {dusk2 }}$ and/or $\phi_{\min }$ can become $\phi_{\text {dawn } 2}$, where $\phi_{\text {dusk } 2}$ 


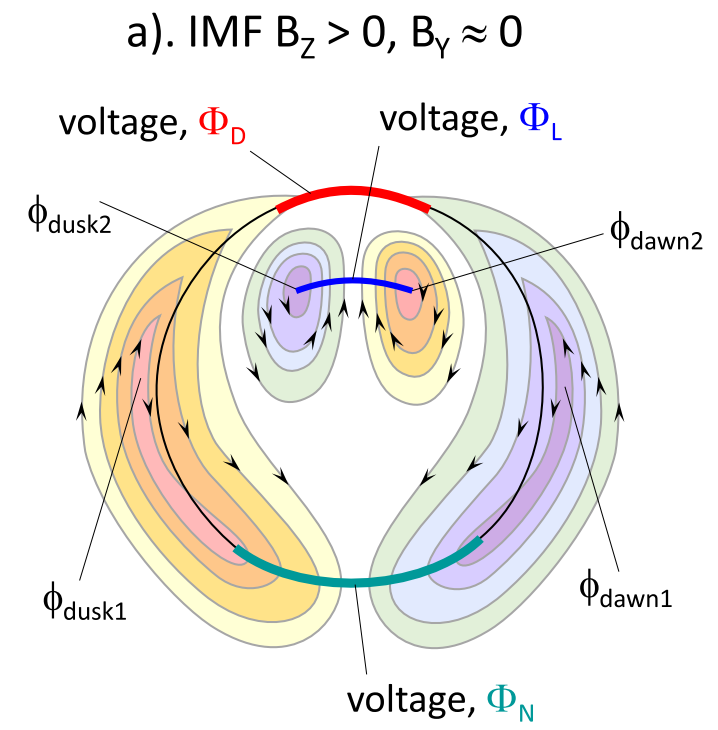

b). IMF $B_{Z}>0, B_{Y}>0$
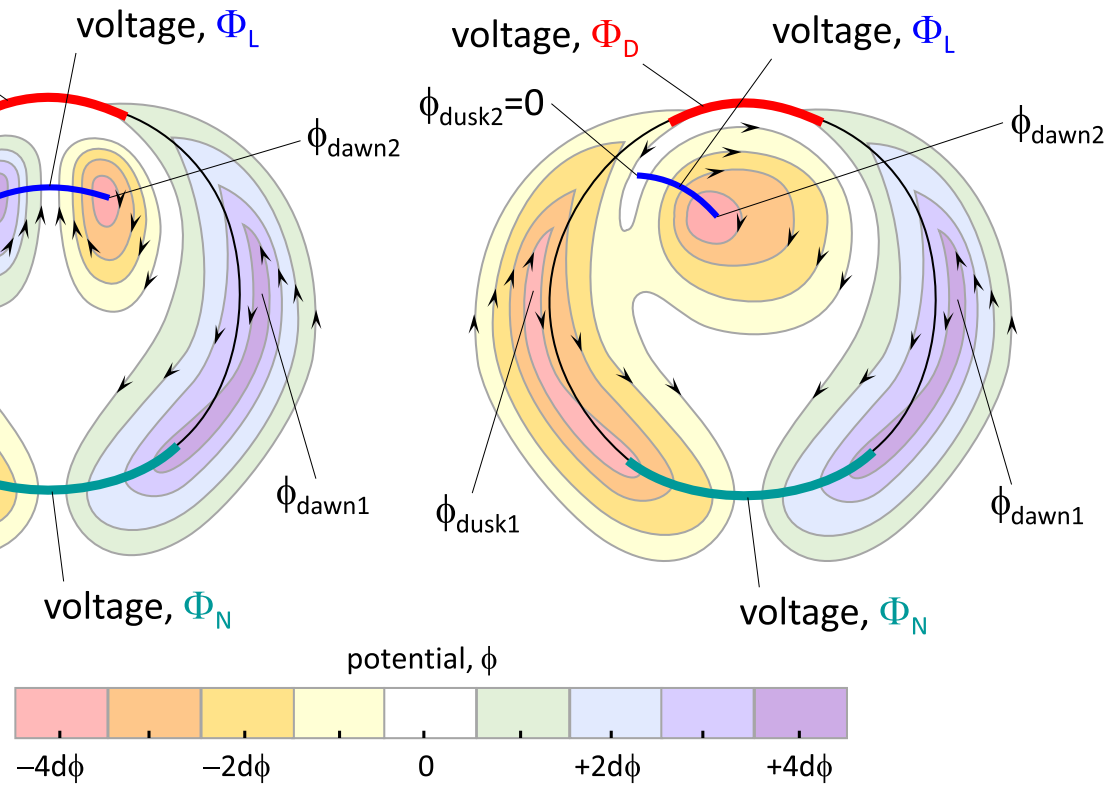

Figure 3. Schematic illustrations of northern-hemisphere ionospheric flow streamlines (equipotentials $d \phi$ apart) during northward interplanetary magnetic field (IMF) $\left(B_{Z}>0\right)$ and under the influence of the three driving voltages $\Phi_{\mathrm{D}}, \Phi_{\mathrm{N}}$, and $\Phi_{\mathrm{V}}$ discussed in Figure 1, plus a lobe reconnection voltage $\Phi_{\mathrm{L}}$. Both the cases are for a contracting polar cap with $\Phi_{\mathrm{N}}>\Phi_{\mathrm{D}}$ giving poleward motion of the adiaroic polar cap boundaries. In part (a), lobe reconnection with IMF $B_{Y} \approx 0$ gives two symmetric lobe circulation cells in the polar cap. Part (b) is an example of a case with large IMF $\left|B_{Y}\right|$ showing the effect of $B_{Y}>0$ in the northern hemisphere, which yields a dominant dawn lobe cell, the sunward flow portion of which can merge with main dusk cell at the lower potentials because of the poleward contraction of the dusk adiaroic polar cap boundary. In part (a), $\Phi_{\mathrm{L}}$ is close to the value of $\Phi_{\mathrm{PC}}$ that is set by $\Phi_{\mathrm{D}}, \Phi_{\mathrm{N}}$, and $\Phi_{\mathrm{V}}$ : in terms of the potential separation $d \phi$, the schematic in part (a) is for $\Phi_{\mathrm{N}}=8 d \phi, \Phi_{\mathrm{D}}=2 d \phi, \Phi_{\mathrm{L}}=8 d \phi$, and $\Phi_{\mathrm{V}}=2 d \phi$. In part (b), $\Phi_{\mathrm{N}}=8 d \phi, \Phi_{\mathrm{D}}=2 d \phi, \Phi_{\mathrm{L}}=4 d \phi$, and $\Phi_{\mathrm{V}}=2 d \phi$.

and $\phi_{\text {dawn2 }}$ appear across the ends of the footprint of the lobe reconnection X-line and are also defined in Figure 3. Hence if $\phi_{\text {dusk2 }}>\phi_{\text {dawn } 1}$ and $\phi_{\text {dawn } 2}<\phi_{\text {dusk1 } 1}$, our definition means that $\Phi_{\mathrm{PC}}=\phi_{\text {dusk } 2}-\phi_{\text {dawn } 2}=\Phi_{\mathrm{L}}$. We will call $\Phi_{\mathrm{PC}}$ in this case a "lobe-dominated" value of $\Phi_{\mathrm{PC}}$ : note that it is a positive value even though the dominant flow in the central polar cap is now sunward. If neither lobe cell sets $\phi_{\min }$ or $\phi_{\max }$ then $\Phi_{\mathrm{PC}}$ is the voltage associated with antisunward convection over the polar cap set by $\Phi_{\mathrm{D}}, \Phi_{\mathrm{N}}$, and $\Phi_{\mathrm{V}}$. We note below that this is the most common situation and hence we call the resulting $\Phi_{\mathrm{PC}}=\phi_{\text {dawn } 1}-\phi_{\text {dusk } 1}$ a "conventional" value. There is a third possibility where $\phi_{\text {dusk2 }}>\phi_{\text {dawn1 }}$ or $\phi_{\text {dawn } 2}<\phi_{\text {dusk } 1}$ but not both. In either of these two cases, $\Phi_{\mathrm{PC}}$ will be somewhat larger than the conventional value and we call this a "hybrid" value as $\Phi_{\mathrm{D}}, \Phi_{\mathrm{N}}$, $\Phi_{\mathrm{V}}$, and $\Phi_{\mathrm{L}}$ can all contribute to $\Phi_{\mathrm{PC}}$. Wilder et al. (2008) have surveyed Super Dual Auroral Radar Network (SuperDARN) data and shown that the lobe reconnection voltage in the ionosphere $\Phi_{\mathrm{L}}$ saturates at about 15-20 kV. This means that voltages above $20 \mathrm{kV}$ are almost all "conventional" values associated with dominant antisunward transfer of flux over the polar cap and set by $\Phi_{\mathrm{D}}, \Phi_{\mathrm{N}}$, and $\Phi_{\mathrm{V}}$. However, for $\Phi_{\mathrm{PC}}<20 \mathrm{kV}$ we need to remain aware that $\Phi_{\mathrm{D}}, \Phi_{\mathrm{N}}, \Phi_{\mathrm{V}}$, and $\Phi_{\mathrm{L}}$ can all contribute to $\Phi_{\mathrm{PC}}$ for the hybrid cases and that for the lobe-dominated cases $\Phi_{\mathrm{PC}}=\Phi_{\mathrm{L}}$. For our definition, the viscous-like voltage $\Phi_{\mathrm{V}}$ would only equal the $\Phi_{\mathrm{PC}}$ value if all the three reconnection voltages $\Phi_{\mathrm{D}}, \Phi_{\mathrm{N}}$, and $\Phi_{\mathrm{L}}$ were zero.

Milan et al. (2021) surveyed 1-year of data and found that roughly $20 \%$ of all antisunward magnetospheric flux transfer was during quiet periods, $43 \%$ during non-steady-state phases $(20.8 \%$ substorm growth, $9.8 \%$ substorm expansion, $3.3 \%$ substorm recovery, $1.2 \%$ recovery bays, and $8 \%$ multiple intensifications). The remaining 37\% was during intervals they classed as "driven"-these include extended substorm growth phases and periods when dayside and nightside reconnection are close to being balanced $\left(\Phi_{\mathrm{D}} \approx \Phi_{\mathrm{N}}\right)$. This driven state was found for $18.2 \%$ of the time, compared to $27.2 \%$ of the time for the non-steady phases. Together, these make up the $50 \%$ of time for which the IMF points southward and, as noted above, northward 
IMF is inherently non-steady and so non-steady conditions are present $77.2 \%$ of the time. Hence, in both time and resulting flux transfer, non-steady conditions are the dominant magnetospheric response. However, we introduce steady state into our view of the coupled magnetosphere-ionosphere system at all times if we average data together. In steady state, the rate of flux transfer across the polar cap, $\Phi_{\mathrm{PC}}$ equals the rate at which field lines are opened by reconnection in the dayside magnetopause (the dayside reconnection voltage $\Phi_{\mathrm{D}}$ ) and the rate at which open field lines are closed by reconnection in the cross-tail current sheet (the nightside reconnection voltage $\Phi_{\mathrm{N}}$ ), plus any non-reconnection "viscous-like" voltage, $\Phi_{\mathrm{V}}$ (i.e., $\left.\Phi_{\mathrm{PC}}=\Phi_{\mathrm{D}}+\Phi_{\mathrm{V}}=\Phi_{\mathrm{N}}+\Phi_{\mathrm{V}}\right)$. The balanced reconnection $\left(\Phi_{\mathrm{D}} \approx \Phi_{\mathrm{N}}\right)$ needed for steady state can occur at any one moment by chance or could be the result of a mechanism that maintains it. As yet, no such mechanism has been defined. Furthermore, there are reasons to believe that no such mechanism can be present: for it to operate, information about the magnetopause reconnection voltage at any one time $\Phi_{\mathrm{D}}$ would have to be able to reach the nightside reconnection site so the mechanism can modulate $\Phi_{\mathrm{N}}$. Because of propagation delays, at the nightside reconnection site there can be no information about the instantaneous value of $\Phi_{\mathrm{D}}$ at the dayside reconnection site, and so $\Phi_{\mathrm{D}} \approx \Phi_{\mathrm{N}}$ cannot happen as a matter of course, maintained by a balancing mechanism. Faraday's law applied to the open-closed field line boundary gives the general behavior:

$$
d F_{\mathrm{o}} / d t=B_{\mathrm{i}} \cdot d A_{\mathrm{o}} / d t=\Phi_{\mathrm{D}}-\Phi_{\mathrm{N}}
$$

where $F_{\mathrm{o}}$ is the open magnetospheric flux, $A_{\mathrm{o}}$ the area of the open field line polar cap in the ionosphere and $B_{\mathrm{i}}$ is the magnitude of the field in the ionosphere (in this equation, $B_{\mathrm{i}}$ is assumed to be constant). Note that Equation 2 can be thought of as the continuity equation for the open flux $F_{\mathrm{o}}$. Hence, steady state requires $\Phi_{\mathrm{D}}=\Phi_{\mathrm{N}}$ and $d F_{\mathrm{o}} / d t=d A_{\mathrm{o}} / d t=0$ and the fact that the polar cap area varies shows that non-steady conditions apply (Holzer et al., 1986; Milan, 2004; Milan et al., 2003). The results of Lockwood et al. (2009) and Milan et al. (2021) show that non-steady state is a common situation, which is to be expected because of the variability in the IMF orientation (and hence $\Phi_{\mathrm{D}}$ ) and the fact that the transfer of information from the dayside magnetopause reconnection site to that in the cross-tail current sheet takes time and hence $\Phi_{\mathrm{N}}$ can only respond after a lag. How common balanced convection $\left(\Phi_{\mathrm{D}} \approx \Phi_{\mathrm{N}}\right)$ events are found to be is a matter of definition (see McWilliams et al., 2008) and they will be less common if tighter limits are placed on the maximum $\left(\Phi_{\mathrm{D}}-\Phi_{\mathrm{N}}\right)$ used to define them. For a large averaging timescale $\tau$, the time derivatives in Equation 2 tend to be zero because long-term trends in $F_{\mathrm{o}}$ and $A_{\mathrm{o}}$ are negligibly small. So, for large enough $\tau$

$$
<\Phi_{\mathrm{PC}}>_{\tau}-<\Phi_{\mathrm{V}}>_{\tau}=<\Phi_{\mathrm{D}}>_{\tau}=<\Phi_{\mathrm{N}}>_{\tau}
$$

even though this condition only applies relatively rarely at any one instant of time.

The voltage $\Phi_{\mathrm{V}}$ is generated by any non-reconnection process transferring momentum from the flow of the shocked solar wind in the magnetosheath to closed field lines (e.g., Farrugia et al., 2001). The ECPC model predicts that $\Phi_{\mathrm{V}}$ is small and that most of what had previously been thought to be voltage driven by viscous-like processes is, in fact, due to the nightside reconnection voltage $\Phi_{\mathrm{N}}$, which always persists because the geomagnetic tail never completely erodes away and so there is always magnetic shear in the center of the tail (Lockwood, 1991; Lockwood et al., 1990; Milan, 2004; Wygant et al., 1983). Numerical simulations have confirmed that $\Phi_{\mathrm{N}}$ contributes to transpolar voltage $\Phi_{\mathrm{PC}}$ in addition to $\Phi_{\mathrm{D}}$ (e.g., Gordeev et al., 2011).

Lockwood (1991) pointed out that a consequence of the ECPC model is that $\Phi_{\mathrm{PC}}$ for a given $\Phi_{\mathrm{D}}, \Phi_{\mathrm{N}}$, and $\Phi_{\mathrm{V}}$ will depend on the shape of the open polar cap and how it changes and only for an open polar cap that remains circular at all times is the voltage across the center of the polar cap equal to $\Phi_{\mathrm{V}}+\left(\Phi_{\mathrm{D}}+\Phi_{\mathrm{N}}\right) / 2$. Hence, in general, for the duration of each polar cap traversal by a LEO satellite, we need to consider nonsteady conditions, and that each $\Phi_{\mathrm{PC}}$ value observed will depend on $\Phi_{\mathrm{D}}, \Phi_{\mathrm{N}}$, and $\Phi_{\mathrm{V}}$ and on how the polar cap is changing shape (i.e., the motion of the adiaroic boundaries which reflect the potential distribution along the boundary) and, critically, on the satellite path. Some changes in the polar cap shape are an integral part of the ECPC flow excitation mechanism proposed by Cowley and Lockwood (1992), specifically the equatorward expansion around noon caused by sudden increases in $\Phi_{\mathrm{D}}$ and the poleward contraction around midnight caused by sudden increases in $\Phi_{\mathrm{N}}$. However, other polar cap shape distortions are likely. Examples include the effects of changes in the IMF $B_{Y}$ component (Cowley, Morelli, \& Lockwood, 1991; Lockwood, 1991) or transient and propagating filamentary field aligned currents in traveling convection vortices induced by solar wind dynamic pressure pulses (e.g., Lühr et al., 1996). In addition, prolonged northward IMF can lead to open flux collecting toward midnight, giving a more triangular open flux region 
characteristic of the "horse-collar" pattern in global auroral images (Birn et al., 1991; Hones et al., 1989): it has been proposed that this is enhanced by lobe reconnection taking place in both the hemispheres which removes dayside open flux (Milan et al., 2020). Hence, the use of a circular open polar cap in Figures 2 and 3 is illustrative only. Nevertheless, in general, satellite passes of the dayside polar cap will reflect the influence of $\Phi_{\mathrm{D}}$ to a greater extent and for passes over the nightside polar cap the influence of $\Phi_{\mathrm{N}}$ will be greater.

The question then arises as to what is the minimum averaging timescale $\tau$ required to make Equation 3 apply to a good approximation? Clearly, $\tau$ smaller than about $3 \mathrm{~h}$ is inadequate as it is comparable to the timescales of the substorm cycle over which the open polar cap expands and contracts (Holzer et al., 1986; Huang et al., 2009; Lockwood \& Cowley, 1992; Lockwood et al., 1990; Milan et al., 2003, 2009, 2012). Imber et al. (2013) show that over the sunspot cycle the polar cap area is remarkably constant, making $d F_{0} /$ $d t$ negligible over timescales $\tau$ of order years. Both modeling (e.g., Lopez et al., 2001) and observational studies (e.g., Mishin \& Karavaev, 2017) show that $F_{0}$ rises during the initial phases of large geomagnetic storms but $F_{\mathrm{o}}$, like $\Phi_{\mathrm{PC}}$ (e.g., Kubota et al., 2017), appears to saturate establishing a temporary quasi-steady state, before falling again as the storm declines. These "balanced reconnection intervals" (BRI) are related to the phenomenon of "steady magnetospheric convection" (SMC) (McWilliams et al., 2008) events but do not necessarily start with a substorm growth phase nor end with a substorm expansion phase (DeJong et al., 2008); however, because in general there is a long-term variation in $F_{\mathrm{o}}$ around both BRI and SMC events (Lockwood et al., 2009; Milan et al., 2021), they cannot be considered a steady-state phenomenon on timescales shorter than their duration. However, we note that some BRI and SMC events probably can occur without prior, or subsequent, major change in $F_{\mathrm{o}}$ and these would be chance occurrences of matched $\Phi_{N}$ and $\Phi_{D}$ variations or because the rate of change in $\Phi_{D}$ has been slow enough for $\Phi_{N}$ to respond despite the propagation lag. Note also that the high variability of IMF orientation, and hence power input into the magnetosphere, gives this a lower occurrence frequency than that of non-steady conditions (Lockwood et al., 2019b, 2019c).

In general, we need $\tau$ to exceed storm durations for steady state to fully apply. Haines et al. (2019) have surveyed geomagnetic storms in the homogeneous $a a$ index, $a a_{H}$ (Lockwood, Chambodut, et al., 2018; Lockwood, Finch, et al., 2018) since 1868, defining storms as when $a a_{H}$ exceeded its overall 90th percentile: of the $10^{4}$ storms defined by this threshold, none lasted more than 3 days. Hence $\tau \geq 3$ days should generally make steady state a valid assumption. We note that Weigel (2007) proposes that the time constant is considerably longer than this, such that non-steady conditions and solar wind history even means that the time of year influences the variation; however, as demonstrated by Lockwood et al. (2016), this would generate an "axial-like" time-of-day/time-of-year pattern and we can discount this proposal.

\subsection{SuperDARN Transpolar Voltage Data and Potential Patterns}

The studies of transpolar voltage discussed in the previous section were made using observations of electric fields and plasma flows by LEO satellites as they passed over the polar caps. One problem with this is that the satellite path will not generally intersect the points of maximum and minimum potential and so the difference between them, the full transpolar voltage $\Phi_{\mathrm{PC}}$, will be systematically underestimated. In addition, because there is no information of the potential pattern away from the satellite path, there is no way of checking if, or by how much, any one value is an underestimate. Studies have generally used passes that are close to the dawn-dusk meridian to try to minimize this problem, but the ECPC model predicts that this will only work for steady state conditions. This is because, as illustrated by Figures $2 \mathrm{~b}$ and $2 \mathrm{c}$, for dominant magnetopause reconnection $\left(\Phi_{\mathrm{D}}>\Phi_{\mathrm{N}}\right)$, both the maximum and minimum of the potential pattern will be shifted toward noon and for dominant tail reconnection $\left(\Phi_{\mathrm{N}}>\Phi_{\mathrm{D}}\right)$ they are shifted toward midnight. In this study, we use values derived from the SuperDARN coherent radar arrays (see review by Chisham et al., 2007). By imaging the convection pattern, the points of maximum and minimum potential can be identified and the problem inherent in the spacecraft data avoided. As discussed in Section 1.1, we adopt the definition of $\Phi_{\mathrm{PC}}$ given in Equation 1 and use an automated algorithm to compute it from patterns of the ionospheric potential, $\phi$.

However, there are some other important points to note about the transpolar voltage data from the SuperDARN radars. The radars monitor the line-of-sight component of the flow of F-region plasma by measuring the Doppler shift of coherent echoes that have reflected off convecting ionospheric irreg- 
ularities embedded in the bulk plasma flow. The most accurate method for generating two-dimensional field-perpendicular convection velocity vectors from the SuperDARN radar data is by combining the line-of-sight measurements within a common field-of-view of pairs of radars (e.g., Greenwald et al., 1995). However, because of the aspect sensitivity of echoes with respect to the structures causing the scatter, for much of the time when echoes are recorded by one radar, they are not detected by the twin radar looking in a different direction and so opportunities to make these "bistatic" observations are relatively rare. Hence, methods to find the functional form for the distribution of electrostatic potential $\phi$ that was a best fit to all the line-of-sight velocity measurements were developed (Cousins et al., 2013; Ruohoniemi \& Baker, 1998). The most widely used of these is the "map-potential" technique (a form of reanalysis using data assimilation), which performed well when tested against available bistatic vectors (Provan et al., 2002). However, lack of radar coverage and/or of the required scattering irregularities mean that line-of-sight data are not available at all the locations in the polar regions and so the velocity data are supplemented with predictions by a statistical model, driven by the IMF conditions observed by an upstream monitor. From each derived map-potential pattern the transpolar voltage $\Phi_{\mathrm{PC}}$ can be scaled (Bristow et al., 2004; Wilder et al., 2011). A review of the development and application of this technique has been presented by Chisham et al. (2007).

The statistical model predictions used in the map-potential technique are weighted to minimize their impact for a given number of available radar echoes, $n_{e}$ (Shepherd $\&$ Ruohoniemi, 2000). At times there are sufficient numbers and wide enough spatial distribution of echoes for the potential pattern to be determined from the radar data alone; on the other hand, in extreme cases with no echoes $\left(n_{\mathrm{e}}=0\right)$, the pattern is determined purely by the model and hence by the observed upstream interplanetary conditions. Tests of flow velocities derived using the SuperDARN radars have been made by comparing the map-potential flow estimates with data from the Defense Meteorological Satellite Program, DMSP (e.g., Drayton et al., 2005; Xu, Koustov, et al., 2007; Xu, Xu, et al., 2007) and Swarm (Koustov, Lavoie, et al., 2019) spacecraft. In addition, transpolar voltage data from the SuperDARN map-potential data have been compared to those derived by the AMIE (Assimilative Mapping of Ionospheric Electrodynamics) technique that uses a variety of sources, particularly magnetometers (Gao, 2012). Given that there is a tendency for flow speeds defined by SuperDARN to be about 30\% lower than seen by satellites (Drayton et al., 2005; Koustov, Lavoie, et al., 2019; Xu, $\mathrm{Xu}$, et al., 2007), but that CRB locations in the two data sets are very similar, we would expect SuperDARN values of $\Phi_{\mathrm{PC}}$ to be well correlated with the satellite values but typically $30 \%$ lower. From the detailed comparison shown in part (c) of Figure A1, allowing for the effect of the number of data echoes $\Phi_{\mathrm{PC}}$ and the proximity of the satellite pass, we find a similar result but the best fit regressions (linear and nonlinear) show that the radar values are typically $20 \%$ lower.

In this paper, we use a variety of threshold values $n_{\min }$ of the number of radar echoes $n_{\mathrm{e}}$ to investigate the effect of low $n_{\mathrm{e}}$ on our results. All $\Phi_{\mathrm{PC}}$ values based on $n_{\mathrm{e}}<n_{\min }$ echoes were discarded, and we varied $n_{\min }$ to determine the sensitivity of our results to the choice of $n_{\min }$.

The use of a $n_{\mathrm{e}}>n_{\min }$ selection criterion has an important but subtle implication for biases in the data because considerably fewer echoes are received during summer. This is probably due to a combination of causes acting together including: sporadic E-blanketing of F-region radar returns; interference from enhanced ground echoes; and a smoother ionosphere when photoionization rate is high and the effects of radar transmitter frequency selection (Koustov, Ullrich, et al., 2019 and references therein). Here, we only use potential maps from the northern hemisphere radar array with its greater number of stations and the means of $n_{\mathrm{e}}$ are consistently about 200 around the June solstice (summer) whereas they are typically between 500 and 600 around the December (solstice) winter. This means that hourly values that meet, for example, a $n_{\mathrm{e}}>n_{\min }=255$ criterion are quite rare in summer and atypical (around 2-3 per day, whereas there are typically $20-24$ per day in winter).

The other factor that we need to be aware of is that the occurrence of echoes also increases with the plasma velocity (Koustov, Ullrich, et al., 2019). This means that although we want to avoid samples with low $n_{\mathrm{e}}$ to minimize the role that the data assimilation statistical convection model plays in the $\Phi_{\mathrm{PC}}$ value, we do not want to eliminate too many samples because that would preferentially remove low-flow (and hence low$\left.\Phi_{\mathrm{PC}}\right)$ samples. 
The ECPC model has been used quantitatively to match to map-potential SuperDARN observations of the evolution of the convection pattern and $\Phi_{\mathrm{PC}}$ following individual events of southward and northward turnings of the IMF (Lockwood et al., 2006), events that were also quantitatively compared with the associated signatures of magnetopause reconnection in cusp proton precipitation and aurora (Lockwood et al., 2003; Throp et al., 2005). Here, we make a statistical study of the $\Phi_{\mathrm{PC}}$ data from SuperDARN using data from 25 years-more than a full Hale solar magnetic cycle.

\section{Data Employed}

In this paper, we make use of 214,410 hourly observations of the ionospheric transpolar voltage $\Phi_{\mathrm{PC}}$, as defined by Equation 1, derived from map potential $\phi$ patterns obtained by the northern-hemisphere SuperDARN radar network between 1995 and 2020. These data are generated by applying the map potential technique to data from 2-min integration periods and the 30 values of $\Phi_{\mathrm{PC}}$ and $n_{\mathrm{e}}$ in each hour were then averaged together. The processed data have been checked using comparisons with dawn-dusk passes by DMSP satellites from 2001 to 2002 for which the SuperDARN convection patterns show potential minima and maxima close to the satellite path (see Appendix A).

We compare with data on the north-south component of the IMF in the GSM frame, $B_{Z}$ (defined positive northward), and the solar wind dynamic pressure, $p_{\mathrm{Sw}}$, both taken from the OMNI data set, compiled and maintained by NASA's Goddard Space Flight Center (King \& Papitashvili, 2005). We also compare with the $A L$ auroral electrojet geomagnetic index compiled and maintained by the World Data Centre for Geomagnetism, Kyoto. We use 1-min values of $B_{Z}, p_{\mathrm{SW}}$, and $A L$. Because we are not sure of the precise propagation lags of these parameters relative to the $\Phi_{\mathrm{PC}}$ data, we take running (boxcar) means over a timescale $\tau$ which we then interpolate to the mid-point of the hour over which $\Phi_{\mathrm{PC}}$ data are averaged, minus a nominal propagation lag $\delta t$. We repeated all studies using two values of $\tau, \tau=1 \mathrm{~h}$ to match the averaging timescale of the $\Phi_{\mathrm{PC}}$ data and $\tau=15 \mathrm{~min}$ : plots for the two were almost identical and we use $\tau=15 \mathrm{~min}$ in the plots shown. For IMF $B_{Z}$, we use a lag $\delta t=5 \mathrm{~min}$, to allow for propagation across the magnetosheath to the dayside magnetopause reconnection $\mathrm{X}$-line and then down geomagnetic field lines to the ionosphere, because we are interested in the effect of IMF $B_{Z}$ on the dayside reconnection voltage $\Phi_{\mathrm{D}}$. For $p_{\mathrm{SW}}$, we have tried two different values of $\delta t$ : to search for an effect of $p_{\mathrm{SW}}$ on $\Phi_{\mathrm{D}}$ we use $\delta t=5 \mathrm{~min}$ as for IMF $B_{Z}$, and to search for an effect of $p_{\mathrm{SW}}$ on $\Phi_{\mathrm{N}}$ we use $\delta t=75 \mathrm{~min}$ (derived below). The latter effect is expected from squeezing of the nearEarth tail, as recently observed and modeled by Lockwood, McWilliams, et al. (2020), Lockwood, Owens, et al. (2020), and Lockwood et al. (2021). Because of the persistence (i.e., a high and broad autocorrelation function) in the $p_{\mathrm{Sw}}$ data series, the results are similar for the two $\delta t$ values; however, slightly clearer effects are seen for $\delta t=75 \mathrm{~min}$ and that is the value employed in the plots presented here. For $A L$, we use $\delta t=0$ as both $A L$ and the $\Phi_{\mathrm{N}}$ value are used as an indicator of signatures in the nightside auroral ionosphere. We compute $p_{\mathrm{SW}}=m_{\mathrm{SW}} N_{\mathrm{SW}} V_{\mathrm{SW}}^{2}$ from 1-min values of the solar wind mean ion mass $m_{\mathrm{SW}}$, number density $N_{\mathrm{SW}}$, and speed $V_{\mathrm{SW}}$; in the case of $m_{\mathrm{SW}}$, these are linearly interpolated from 5, $15 \mathrm{~min}$ or hourly observations if 1-min values are unavailable.

We note that a great many papers derive propagation delays $\delta t$ between solar wind features and responses in the magnetosphere and ionosphere. These are not always comparable because different solar wind features and different responses are considered. In addition, some effects call for the IMF orientation to be considered whereas others do not. In addition, the solar wind speed varies and alters the $\delta t$ values. Some studies use correlations to define the peak response whereas others use the timing of the first detectable response. A detailed and extensive statistical study of the delay between changes in the IMF $B_{Y}$ component and their effect appearing in the near-Earth tail lobes and plasma sheet was presented by Browett et al. (2017). They found optimum delays of $1 \mathrm{~h}$ for southward IMF but up to $5 \mathrm{~h}$ for northward IMF conditions. Because these are the times for the magnetic curvature force to take effect in the tail, they relate to field-aligned Alfvén wave propagation times as well as solar wind propagation times and so are not directly comparable with, for example, the propagation time for dynamic pressure change effects in the tail. We note that the value of $\delta t=75 \mathrm{~min}$ that we here derive and use, is slightly longer than the 60 min that Browett et al. (2017) derive for southward IMF but much shorter than 300 min that they find sometimes derived for northward IMF. 


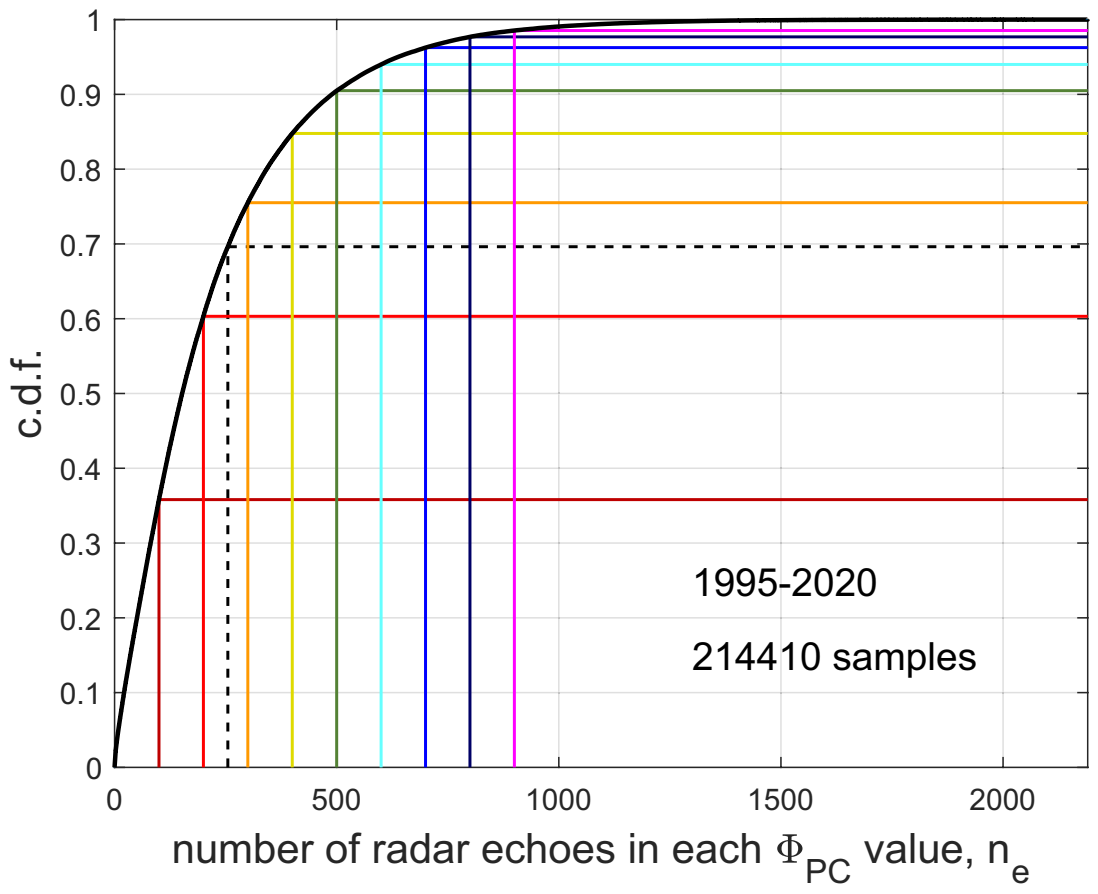

Figure 4. Cumulative probability distribution of the number of radar echoes, $n_{\mathrm{e}}$, used in compiling the convection patterns, and hence the transpolar voltage $\Phi_{\mathrm{PC}}$ estimates, in the data set employed here of $214,410 \Phi_{\mathrm{PC}}$ hourly mean values obtained from the Super Dual Auroral Radar Network radar array using the map potential technique between 1995 and 2020. The vertical lines are various threshold values $n_{\min }$ used in this paper in which $n_{\mathrm{e}}$ must exceed for the $\Phi_{\mathrm{PC}}$ value obtained to be considered valid. The vertical-colored lines are at $n_{\min }$ of [100:100:900] and the black dashed line is at 255. The condition $n_{\mathrm{e}}>n_{\min }=255$ was found to be optimum in a comparison with 2-year data from satellite passes (for 2001 and 2002, see Appendix A) and which yields $N=60,653$ valid $\Phi_{\mathrm{PC}}$ estimates which is close to $30 \%$ of all the observations. The colored thresholds are here used in a sensitivity study to understand the effect of the adopted $n_{\min }$ threshold.

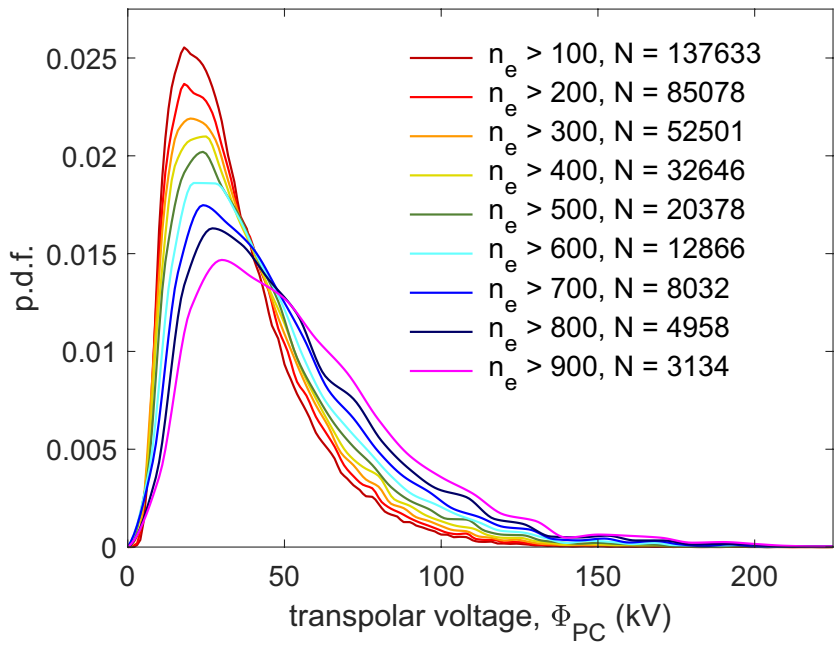

Figure 5. Probability density functions giving the normalized distributions of the $\Phi_{\mathrm{PC}}$ values for threshold values for the number of echoes $n_{\mathrm{e}}$ required of $n_{\min }=$ [100:100:900]. The resulting total number of $\Phi_{\mathrm{PC}}$ values in the data set meeting that requirement, $N$, is given in each case.

\section{Results}

\subsection{Effect of Number of Radar Echoes, $n_{\mathrm{e}}$}

Figure 4 shows the cumulative probability distribution of the hourly means of the number of radar echoes $n_{\mathrm{e}}$ for the 214,410 hourly means of the ionospheric transpolar voltage, $\Phi_{\mathrm{PC}}$. The vertical colored lines show a set of nominal values of $n_{\min }$, which $n_{\mathrm{e}}$ must exceed and which we vary from 100 (dark red) to 900 (mauve) in steps of 100 in our sensitivity study (i.e., $n_{\min }=$ [100:100:900]). These values yield subsets of $137,633,85,078$, $52,501,32,646,20,378,12,866,8,032,4,958$, and 3,134 samples. The black dashed line is for $n_{\min }=255$ which we discuss below, and which yields 60,653 samples, very close to $30 \%$ of the original data set.

Figure 5 shows the probability distribution functions for hourly transpolar voltage, $\Phi_{\mathrm{PC}}$, selected using the condition $n_{\mathrm{e}}>n_{\min }$ for the values of $n_{\min }$ used in Figure 4. It can be seen that the shape of the distribution varies with $n_{\min }$, the mode value of the normalized distribution getting smaller and moving to higher values. The large-value tail of the distribution therefore gets relatively larger, as expected from the discussion in Section 1.2. It can be seen that for $n_{\min }<300$ the effect on the distribution shape is, however, relatively minor.

To further define an optimum value for $n_{\min }$, we have carried out a comparison with dawn-dusk passes by DMSP satellites for the years 2001 and 2002 


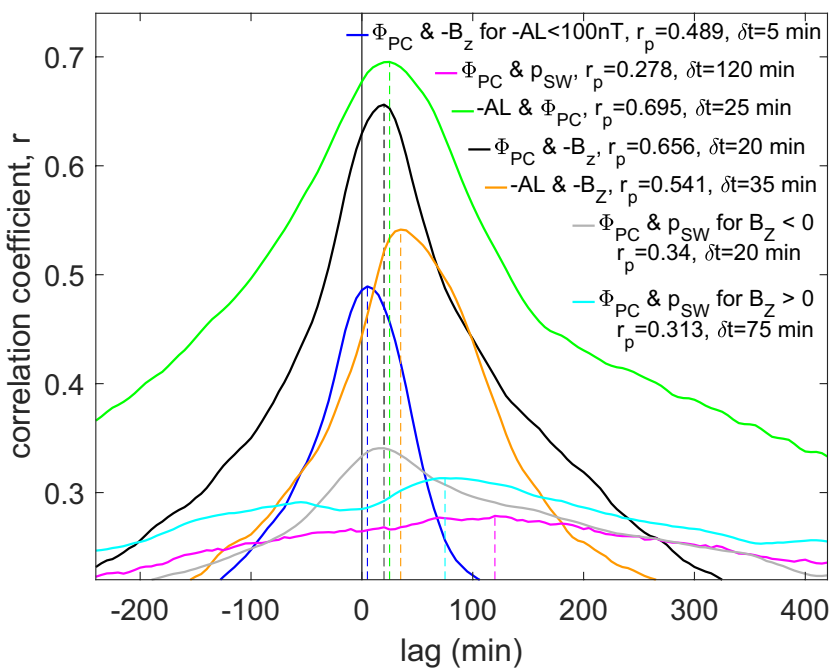

Figure 6. Lag correlograms used to determine the optimum lags $\delta t$ : (black) for $\Phi_{\mathrm{PC}}$ and interplanetary magnetic field (IMF) $-B_{Z}$ (in the geocentric solar magnetospheric [GSM] frame); (blue) for $\Phi_{\mathrm{PC}}$ and IMF $B_{Z}$ (in the GSM frame) for the subset with $-A L<100 \mathrm{nT}$; (orange) for the $-A L$ index and IMF $-B_{Z}$; (green) the $-A L$ index and $\Phi_{\mathrm{PC}}$. The mauve, gray, and cyan lines are for $\Phi_{\mathrm{PC}}$ and the solar wind dynamic pressure $p_{\mathrm{Sw}}$ : mauve is for all data, gray for southward $\operatorname{IMF}\left(B_{Z}<0\right)$, and cyan for northward $\operatorname{IMF}\left(B_{Z}>0\right)$. In each case, the first parameter of the pair has been lagged with respect to the second by the lag given by the $x$-axis. The vertical dashed lines are at the lag $\delta t$ yielding maximum $r, r_{\mathrm{p}}$, and the values for $\delta t$ and $r_{\mathrm{p}}$ are given for each case in the legend. All data are selected by the $\Phi_{\mathrm{PC}}$ data set for $n_{\mathrm{e}}>n_{\min }=255$ radar echoes. and compared the transpolar voltage derived, $\left[\Phi_{\mathrm{PC}}\right]_{\mathrm{DMSP}}$, with the simultaneous SuperDARN map potential estimates, $\left[\Phi_{\mathrm{PC}}\right]_{\text {s.DARN }}$. We computed the root mean square deviation, $\left(\left\langle\Delta \Phi_{P C}^{2}\right\rangle\right)^{1 / 2}$ (where $\Delta \Phi_{\mathrm{PC}}=\left[\Phi_{\mathrm{PC}}\right]_{\mathrm{DMSP}}-$ $\left.\left[\Phi_{\mathrm{PC}}\right]_{\text {s.DARN }}\right)$ as a metric of agreement. In general, we found $\Delta \Phi_{\mathrm{PC}}$ tended to be positive, consistent with the studies discussed in Section 1.2. We used the Nelder-Mead search to find a minimum in $\left(\left\langle\Delta \Phi_{P C}^{2}\right\rangle\right)^{1 / 2}$ as a function of $n_{\min }$ and the maximum allowed geocentric angular separation of the satellite and radar potential maxima and minima, $\delta$. This yielded an optimum $n_{\min }$ of 255 and for the optimum maximum $\delta$ of $30^{\circ}$. The use of $n_{\min }=255$ gave a peak correlation between [ $\left.\Phi_{\mathrm{PC}}\right]_{\mathrm{DMSP}}$ and [ $\left.\Phi_{\mathrm{PC}}\right]_{\text {S.DARN }}$ of 0.85 with and r.m.s. deviation $\left(\left\langle\Delta \Phi_{P C}^{2}\right\rangle\right)^{1 / 2}=18.5 \mathrm{kV}$, compared to a correlation of 0.82 for $n_{\min }=0$, for which $\left(\left\langle\Delta \Phi_{P C}^{2}\right\rangle\right)^{1 / 2}=21.2 \mathrm{kV}$ (see Appendix A). Hence, the agreement was most improved by adopting $n_{\min }=255$, which is a value small enough not to greatly change the shape of the overall distribution of $\left[\Phi_{\mathrm{PC}}\right]_{\text {S.DARN }}$ values, as shown by Figure 5 . We also used this survey to calibrate the SuperDARN estimates: where comparisons are made, we here correct the systematically higher values (by a factor of $20 \%$ ) from the satellite observations using the linear regression of the $\left[\Phi_{\mathrm{PC}}\right]_{\mathrm{DMSP}}$ and $\left[\Phi_{\mathrm{PC}}\right]_{\mathrm{S} . \mathrm{DARN}}$ data for $n_{\min }=255$ and $\delta<30^{\circ}$ (see Appendix A).

In Sections 3.2-3.4 of this paper, we employ the selection criterion $n_{\mathrm{e}}>n_{\min }=255$ (which gives us 60,653 samples). However, in Section 3.5, we return to using all the $n_{\min }$ values used in Figures 4 and 5 in a sensitivity study to show that our conclusions are not influenced by the value of $n_{\text {min }}$ adopted.

\subsection{Variation of $\Phi_{\mathrm{PC}}$ With IMF $B_{Z}$ and the $A L$ Index}

Figure 6 analyses the optimum propagation lags needed for this study. The black line is the lag correlogram (linear correlation coefficient as a function of lag) for $\Phi_{\mathrm{PC}}$ and the IMF- $B_{Z}$ value (in the GSM frame). The peak correlation is with $\Phi_{\mathrm{PC}}$ lagging behind $B_{Z}$ by $\delta t=20 \mathrm{~min}$. This is longer than the response time for dayside magnetopause reconnection (Etemadi et al., 1988; Todd et al., 1988): from the propagation delay to cross the magnetosheath, this is expected to be about $5 \mathrm{~min}$, which is the typical response time seen in the observational studies discussed in Section 1.1. The propagation of the enhancement to the center of the polar cap was modeled using the ECPC model by Morley and Lockwood (2005) and a value of $20 \mathrm{~min}$ from the nose of the bow shock is broadly consistent with their predictions. Figure $2 b$ shows that if the nightside reconnection voltage $\Phi_{\mathrm{N}}$ is small, the transpolar voltage $\Phi_{\mathrm{PC}}$ is approximately equal to $\Phi_{\mathrm{D}}$ and if we also fold in a nonzero viscous voltage this becomes $\Phi_{\mathrm{PC}} \approx \Phi_{\mathrm{D}}+\Phi_{\mathrm{V}}$. In addition, Figure $2 \mathrm{~b}$ shows that this voltage appears between maximum and minimum potentials at points that are close to the ends of the ionospheric footprint of the magnetopause reconnection X-line. In this case, the response of $\Phi_{\mathrm{PC}}$ to IMF $B_{Z}$ would be after the short lag with which $\Phi_{\mathrm{D}}$ responds (i.e., $\delta t \approx 5 \mathrm{~min}$ ). The $A L$ index is expected to be a good proxy for the nightside voltage $\Phi_{\mathrm{N}}$, becoming more negative as $\Phi_{\mathrm{N}}$ increases. Hence, a subset of the data selected for a small $-A L$ should give $\Phi_{\mathrm{PC}}$ values dominated by $\Phi_{\mathrm{D}}$ and hence show a small response lag. For the subset of data, when the $A L$ index is above $100 \mathrm{nT}$ (i.e., $-A L<100 \mathrm{nT}$ ), shown by the blue line in Figure 6, the observed lag of $\Phi_{\mathrm{PC}}$ lag after $B_{Z}$ of $\delta t=5 \mathrm{~min}$ is therefore consistent with the ECPC model and low $\Phi_{\mathrm{N}}$. A notable feature of all the correlograms in Figure 6, except those for $\Phi_{\mathrm{PC}}$ and $B_{Z}$ (in blue and black), is that the peaks are asymmetric with higher correlations at a given time after the peak than for the same time before it. This shows that higher auroral activity (i.e., larger negative $A L$ ) are responses over longer time constants and that time constant is variable. The orange line shows that the optimum lag for the $A L$ index after $B_{Z}$ is $\delta t=35 \mathrm{~min}$, but the peak is lower and broader indicating there is considerable variability in that lag. The green line gives the lag of the $A L$ index after $\Phi_{\mathrm{PC}}$ of $\delta t=25 \mathrm{~min}$, which yields a total lag of $25+20=45 \mathrm{~min}$ 


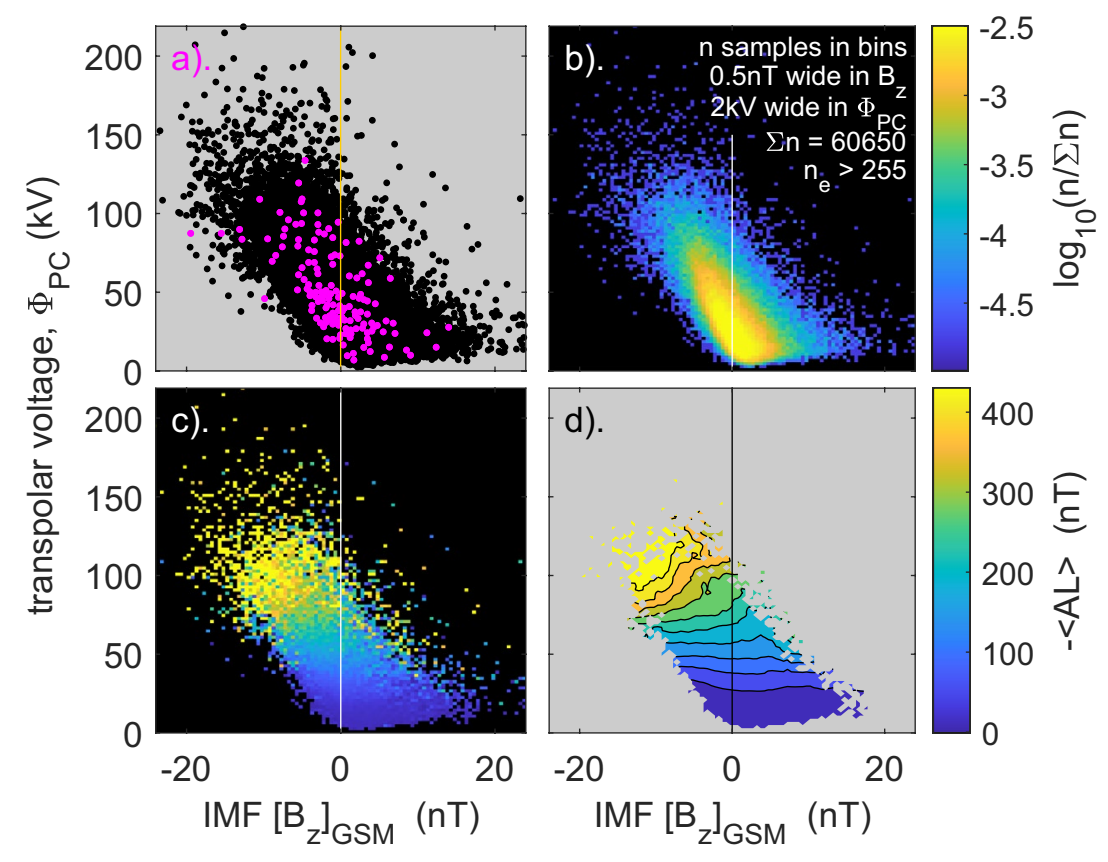

Figure 7. (a) Scatter plots of transpolar voltage estimates $\Phi_{\mathrm{PC}}$ as a function of the IMF $B_{Z}$ component. The black points are for the survey of Super Dual Auroral Radar Network presented here (for $n_{\mathrm{e}}>255$ ) and the mauve points are from the survey of data from various spacecraft by Cowley (1984). (b) The fraction of samples $n / \Sigma n$ (on a logarithmic scale) in bins that are $\Delta B_{Z}=0.5 \mathrm{nT}$ wide in interplanetary magnetic field (IMF) $B_{Z}$ (in the geocentric solar magnetospheric [GSM] frame of reference) and $\Delta \Phi_{\mathrm{PC}}=2 \mathrm{kV}$ wide in the $\Phi_{\mathrm{PC}}$, as a function of $B_{Z}$ and $\Phi_{\mathrm{PC}}$. The IMF $B_{Z}$ data are 15min boxcar running means of 1-min observations and for the optimum lag found in Figure 6. (c) The simultaneous mean negative $A L$ index $-\left\langle A L>\right.$ in the same bins as used in part (b). In both the panels, only $\Phi_{\mathrm{PC}}$ values based on $n_{\mathrm{e}}>255$ radar echoes are used and bins with no samples are shaded black. Part (d) shows the same data as part (c), fitted with contour levels. Note, in relation to part (a), Cowley (1984) presented the data in terms of the dawn-to-dusk interplanetary electric field, $E_{Y}=V_{\mathrm{SW}} B_{Z}$ whereas here we use an $x$-axis of $B_{Z}=E_{Y} / V_{\mathrm{SW}}$. Also, the satellite $\Phi_{\mathrm{PC}}$ data have been scaled to the radar values using the best-fit linear regression shown in part (c) of Figure A1.

after IMF $B_{Z}$ which is 10 min longer than the value obtained from the direct correlation between $A L$ and IMF $B_{Z}$. The mauve line shows the correlation between $\Phi_{\mathrm{PC}}$ and solar wind dynamic pressure $p_{\mathrm{SW}}$, which is considerably weaker than the other correlations, as expected because $\Phi_{\mathrm{PC}}$ depends primarily on $\Phi_{\mathrm{D}}$ and $\Phi_{\mathrm{N}}$, which are not expected to be as strongly modulated by $p_{\mathrm{SW}}$ as they are by $B_{Z}$. However, this $\Phi_{\mathrm{PC}}$ versus $p_{\mathrm{SW}}$ correlogram does show a broad, weak peak with a maximum at a lag of $\delta t=120 \mathrm{~min}$. This suggests that if $p_{\mathrm{SW}}$ is exerting an influence on $\Phi_{\mathrm{PC}}$ it is mainly through a modulation of $\Phi_{\mathrm{N}}$ through squeezing the near-Earth cross-trail current sheet. This will be discussed further in Section 3.3. The correlation between $\Phi_{\mathrm{PC}}$ and $p_{\mathrm{SW}}$ was also examined for northward and southward IMF conditions separately by selecting data when the $B_{Z}$ data simultaneous with $p_{\mathrm{Sw}}$ was positive and negative, giving the cyan and gray correlograms, respectively. For southward IMF, the peak effect is soon after that of the peak response to IMF $B_{Z}$ and so this appears to show an influence of $p_{\mathrm{SW}}$ on the dayside reconnection voltage $\Phi_{\mathrm{D}}$. On the other hand, the peak response for northward IMF is at a lag of $\delta t=75 \mathrm{~min}$ and because of the absence of large $\Phi_{\mathrm{D}}$ in these cases, this appears to show a response of $\Phi_{\mathrm{N}}$ to increased $p_{\mathrm{SW}}$ in these cases (see discussion by Lockwood, 2013). In our studies, we used $\delta t$ of 5, 75, and $120 \mathrm{~min}$ for the optimum lag between $p_{\mathrm{Sw}}$ and terrestrial responses: because of the high persistence in the $p_{\mathrm{Sw}}$ data series the results were very similar in the three cases, and we here show values for $\delta t=75 \mathrm{~min}$.

A great many studies have presented scatter plots of $\Phi_{\mathrm{PC}}$ as a function of IMF $B_{Z}$ (or dawn-dusk interplanetary electric field $V_{\mathrm{SW}} B_{Z}$, but the radial solar wind speed $V_{\mathrm{SW}}$ explains very little of the scatter) and shown that $\Phi_{\mathrm{PC}}$ increases approximately linearly with $-B_{Z}$ for $B_{Z}<0$ but has approximately constant and small values for $B_{Z}>0$. Figure 7a shows that the SuperDARN data set used here also confirms this behavior by comparing a scatter plot of the $\Phi_{\mathrm{PC}}$ values as a function of IMF $B_{Z}$ (black points) with the corresponding scatter plot from the survey of Cowley (1984) using data from a variety of LEO spacecraft (mauve points). 
Note that the satellite $\Phi_{\mathrm{PC}}$ values have been reduced by the $20 \%$ factor found from comparisons with 2 years' passes by the DMSP satellites (see Appendix A). Because there are so many samples in our study, a scatter plot loses a great deal of information because so many points are plotted on top of each other. Hence in Figure $7 \mathrm{~b}$, we color-code the fraction of samples ( $n / \Sigma n$, on a logarithmic scale) in bins of narrow width in both $\Phi_{\mathrm{PC}}$ and $B_{Z}$. The bins used are $\Delta B_{Z}=0.5 \mathrm{nT}$ wide in IMF $B_{Z}$ and $\Delta \Phi_{\mathrm{PC}}=2 \mathrm{kV}$ wide in the $\Phi_{\mathrm{PC}}$. The plot shows the features that are familiar from other plots. Two important features to note are that: (a) for southward IMF there is a considerable spread in $\Phi_{\mathrm{PC}}$ at a given $B_{Z}$, and (b) for northward IMF that spread decreases with increasingly positive $B_{Z}$. The plot also shows that $\Phi_{\mathrm{PC}}$ values increase slightly with increasingly positive $B_{Z}$, which implies that the lobe reconnection voltage $\Phi_{\mathrm{L}}$ increasingly becomes a factor, as discussed in relation to Figure 3.

In the ECPC model, the spread at a given IMF $B_{Z}$ is expected because in non-steady state both $\Phi_{\mathrm{D}}$ and $\Phi_{\mathrm{N}}$ contribute to $\Phi_{\mathrm{PC}}$. From long-term averages (for which $\Phi_{\mathrm{PC}}=\Phi_{\mathrm{D}}+\Phi_{\mathrm{V}}$ ), we know that $\left(\Phi_{\mathrm{D}}+\Phi_{\mathrm{V}}\right)$ varies approximately linearly with $-B_{Z}$ for $B_{Z}<0$. It is also known that the auroral electrojet indices $A E$ and $A L$ vary approximately linearly with $\Phi_{\mathrm{PC}}$, again with considerable scatter (Weimer et al., 1990). In this paper, we investigate the nightside auroral electrojet index $A L$ as a proxy for the nightside voltage, $\Phi_{\mathrm{N}}$, which is consistent with its use as a substorm expansion phase identifier in substorm cycles. Lockwood et al. (2009) used satellite passes to show that, statistically, polar cap flux decayed (i.e., $\Phi_{\mathrm{N}}$ is enhanced) during substorm expansion phases when $-A L$ is enhanced. Hubert, Milan, et al. (2006), Hubert, Palmroth, et al. (2006), and Milan et al. (2009) used auroral images to also infer the loss of open flux during substorm expansion phases, which also implies a relationship between $-A L$ and $\Phi_{\mathrm{N}}$. The variation of $\Phi_{\mathrm{N}}$ inferred from time-constants by Laundal et al. (2020) shows a strong variation with $-A L$, as does the analysis of the polar cap boundary location by Aikio et al. (2013).

Figure 7c shows the mean simultaneous $A L$ values in the same bins as used in Figure $7 \mathrm{~b}$ whereas Figure $7 \mathrm{~d}$ shows contours of these mean $A L$ data. Note, that these contours can only be fitted in areas where the data are not sparse (identified by Figure $7 \mathrm{~b}$ ). It can be seen that the spread in $\Phi_{\mathrm{PC}}$ at a constant $B_{Z}$ is indeed associated with the spread in $A L$, as predicted by the ECPC model.

Figure 8a plots the variation of the occurrence of combinations of the $A L$ index and lagged IMF $B_{Z}$ using the same bins in $B_{Z}$ as used in Figures $7 \mathrm{~b}$ and $7 \mathrm{c}$ and bins of $A L$ that are $10 \mathrm{nT}$ wide. Figure $8 \mathrm{~b}$ shows the mean $\Phi_{\mathrm{PC}}$ in the same bins as used in Figures 8a whereas Figure 8c shows the fitted contours of mean $\Phi_{\mathrm{PC}}$ from the same data. The tilt of the contours toward the diagonal in $8 \mathrm{c}$ clearly shows that $\Phi_{\mathrm{PC}}$ depends on both $B_{Z}$ and $A L$ : at constant $A L, \Phi_{\mathrm{PC}}$ increases with increasingly negative $B_{Z}$ (moving horizontally to the left of the plot) but importantly, $\Phi_{\mathrm{PC}}$ also increases with increasingly negative $A L$ at constant $B_{Z}$ for $B_{Z}<0$ (moving vertically up the left-hand half of the plot). Hence, $\Phi_{\mathrm{PC}}$ increases with increases in both IMF $-B_{Z}$ and $-A L$.

\subsection{Evolution of $\Phi_{P C}$ During Northward IMF With Time Since the IMF Turned Northward}

A second scatter plot that was important verification of the ECPC model was presented in Figure 6 of Wygant et al. (1983). The plot looked at $\Phi_{\mathrm{PC}}$ values during northward IMF, as a function of time $\Delta t$ since the lagged IMF last had a southward component. Shortly after a northward turning (small $\Delta t$ ), Wygant and coworkers found that almost the same range in $\Phi_{\mathrm{PC}}$ was present as had been seen during the prior periods of southward IMF. However, with increased time after the northward turning (larger $\Delta t$ ), this range decreased because the largest observed $\Phi_{\mathrm{PC}}$ declined exponentially. This decline continued until after about $10 \mathrm{~h}$, only low values of $\Phi_{\mathrm{PC}}$ were seen. This behavior is uniquely explained by the ECPC model, which predicts that the larger values of $\Phi_{\mathrm{PC}}$ seen when the IMF is northward are because there is a large $\Phi_{\mathrm{N}}$ (despite $\Phi_{\mathrm{D}}$ being small because the IMF was northward). Large $\Phi_{\mathrm{N}}$ can still be present because of the large open flux that had been produced in the growth phase prior to the northward turning of the IMF, there being a delay before that flux is fully appended to the near-tail tail lobes by the solar wind flow. The inference was that the longer the IMF remained northward, the more events of higher $\Phi_{\mathrm{N}}$ had depleted the open flux and so the maximum of subsequent events was reduced.

The Wygant et al. plot contained only 28 datapoints, it is here reproduced in Figure 9a for the 29,373 datapoints available from our survey for IMF $B_{Z}>0$ and $n_{\mathrm{e}}>255$. To evaluate the time since the IMF had a southward component, we here use 6-min boxcar running means of IMF $B_{Z}$ to avoid periods of northward 


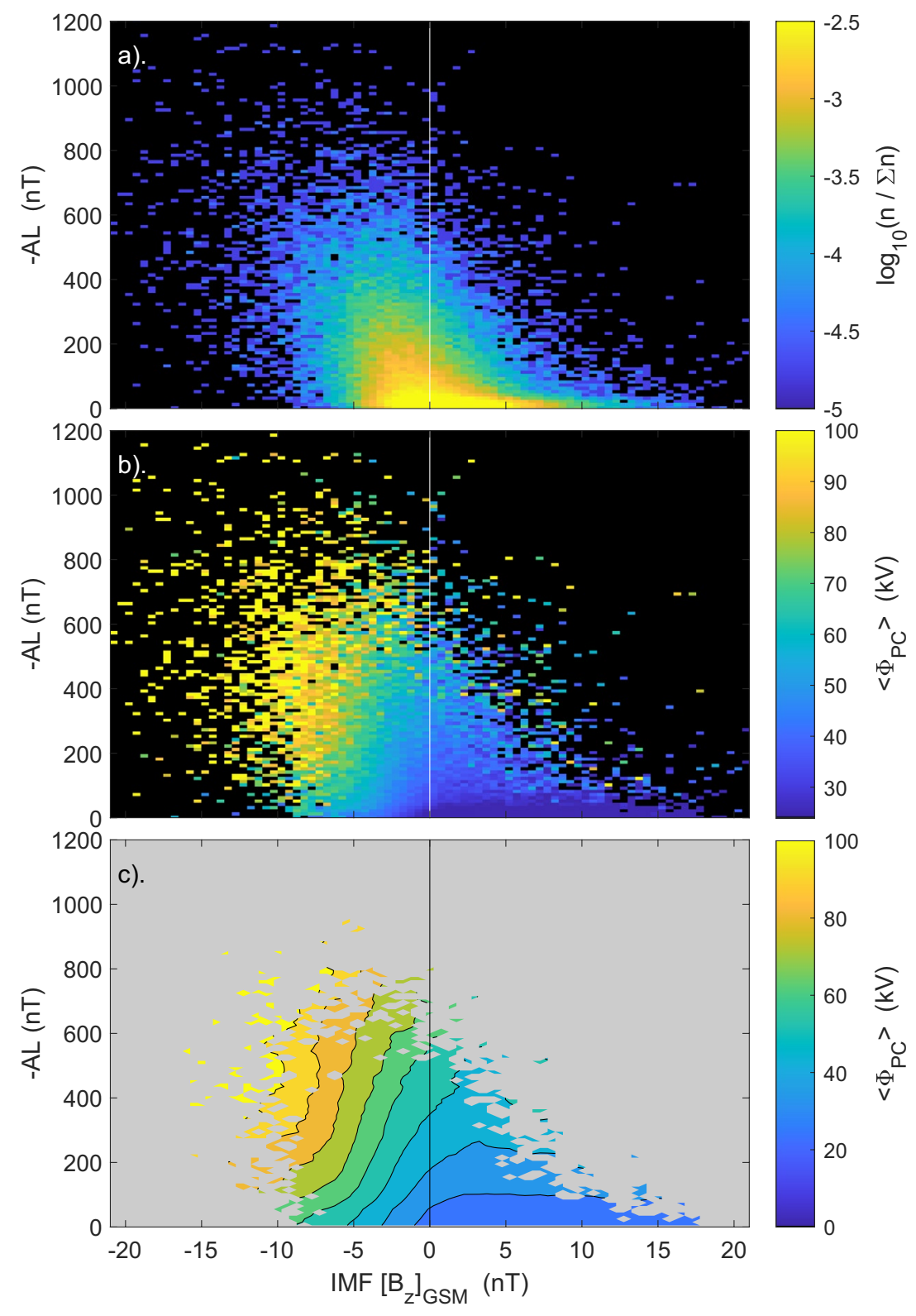

Figure 8. Plots on lagged interplanetary magnetic field (IMF) $B_{Z}$ component and $A L$ index axes of (a) the fraction of samples $n / \Sigma n$ (on a logarithmic scale) and (b) mean transpolar voltage $\left\langle\Phi_{\mathrm{PC}}>\right.$ in bins that are $\Delta B_{Z}=0.5 \mathrm{nT}$ wide in IMF $B_{Z}$ (in the geocentric solar magnetospheric [GSM] frame of reference) and $\triangle A L=10 \mathrm{nT}$ wide in the $A L$ index, as a function of $B_{Z}$ and $-A L$. Both $B_{Z}$ and $A L$ data are 15-min boxcar running means of 1-min observations. Bins with no samples are shaded black. Only $\Phi_{\mathrm{PC}}$ values based on $n_{\mathrm{e}}>255$ radar echoes are used. Part (c) shows the same data as part (b), fitted with contour levels.

IMF being interrupted by just a brief interval of southward IMF. For each northward-IMF $\Phi_{\mathrm{PC}}$ value observed at time $t_{0}$, we evaluate the time at which the lagged IMF turned northward in these 6-min running means, $t_{\mathrm{n}}$, and hence $\Delta t=t_{\mathrm{o}}-t_{\mathrm{n}}$. We did also try using running means over 15 and 60 min and Figure 9 was not substantially changed other than the appropriate resolution in $\Delta t$ was lowered. Again, because of the large number of samples, we color code the fraction of samples $n / \Sigma n$ (on a logarithmic scale) and all panels of Figure 9 uses bins in $\Phi_{\mathrm{PC}}$ that are $2 \mathrm{kV}$ wide (as in Figures 7 and 8) and in $\Delta t$ that are 6 min wide. The near-exponential decay of the largest $\Phi_{\mathrm{PC}}$ found by Wygant and coworkers is clear in Figure 9a and the time constant for that decay is very similar, with $\Phi_{\mathrm{PC}}$ reduced to almost constant value by $\Delta t=15 \mathrm{~h}$. The ECPC model predicts that the larger $\Phi_{\mathrm{PC}}$ values at a given $\Delta t$ will be due to larger $\Phi_{\mathrm{N}}$ and hence greater $-A L$. 


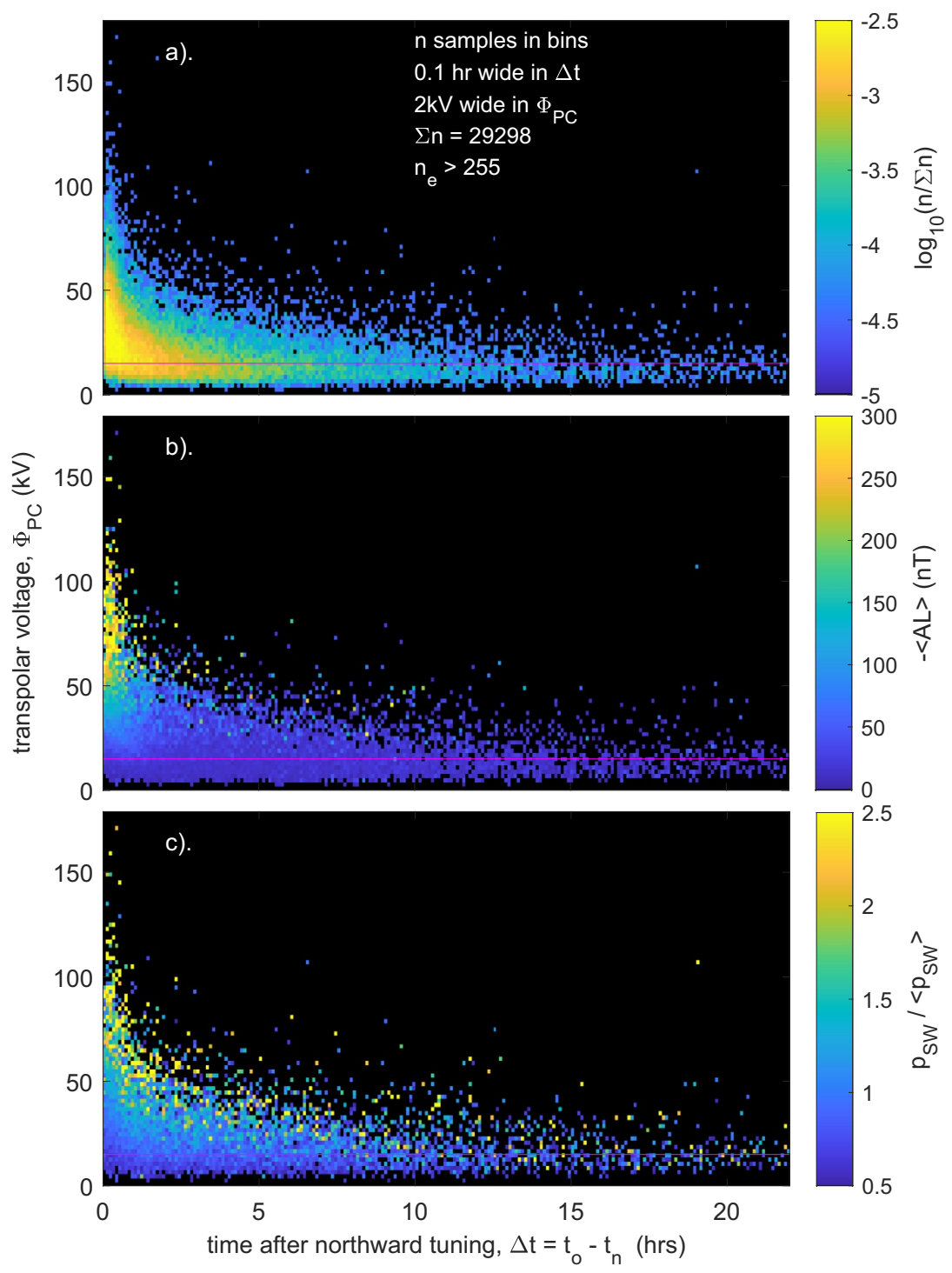

Figure 9. (a) The fraction of samples $n / \Sigma n$ (on a logarithmic scale) during continuous northward interplanetary magnetic field (IMF) $\left(B_{Z}>0\right.$ in the geocentric solar magnetospheric [GSM] frame of reference, using 15-min boxcar running means of lagged 1-min IMF data) as a function of $\Phi_{\mathrm{PC}}$ and the time that the IMF has been northward, $\Delta t=\left(t_{0}-t_{\mathrm{n}}\right)$, where $t_{\mathrm{o}}$ is the time of the $\Phi_{\mathrm{PC}}$ observation and $t_{\mathrm{n}}$ is the time at which the IMF turned northward, in bins that are $0.1 \mathrm{~h}$ wide in $\Delta t$ and $2 \mathrm{kV}$ wide in $\Phi_{\mathrm{PC}}$. (b) The same as (a) for the mean negative $A L$ index $-<A L>$. (c) The same as (a) for the normalized solar wind dynamic pressure, $p_{\mathrm{sw}} /\left\langle p_{\mathrm{SW}}\right\rangle$. In all the three panels, only $\Phi_{\mathrm{PC}}$ values based on $n_{\mathrm{e}}>255$ radar echoes are used and bins with no samples are shaded black.

Figure $9 \mathrm{~b}$ confirms that this is indeed the case by color-coding the mean of $-A L$ in the same bins as used in Figure 9a. Wilder et al. (2008) have used SuperDARN data to show that the lobe reconnection voltage in the ionosphere saturates at about 15-20 kV. From this, we deduce that the voltages shown in Figure 9 for $\Delta t$ greater than about $15 \mathrm{~h}$ after the IMF turned northward are consistent with the effects of lobe reconnection. On the other hand, the values above $20 \mathrm{kV}$ at $\Delta t$ below about $10 \mathrm{~h}$ (when $A L$ is also enhanced) are not and we attribute these to enhanced $\Phi_{\mathrm{N}}$.

Because we are belatedly reproducing the highly significant plot by Wygant et al. (1983), it is worth making a direct comparison. This is done as two superposed scatter plots of $\Phi_{\mathrm{PC}}$ as a function of time since the IMF was last southward $\Delta t$ in the top panel of Figure 10. The black dots are from the present survey, the mauve dots are the data of Wygant et al. (1983). As in Figure 7, the satellite $\Phi_{\mathrm{PC}}$ values have been reduced by the $20 \%$ found in the comparison in Figure A1c. It can be seen that the trend inferred by Wygant et al. from 


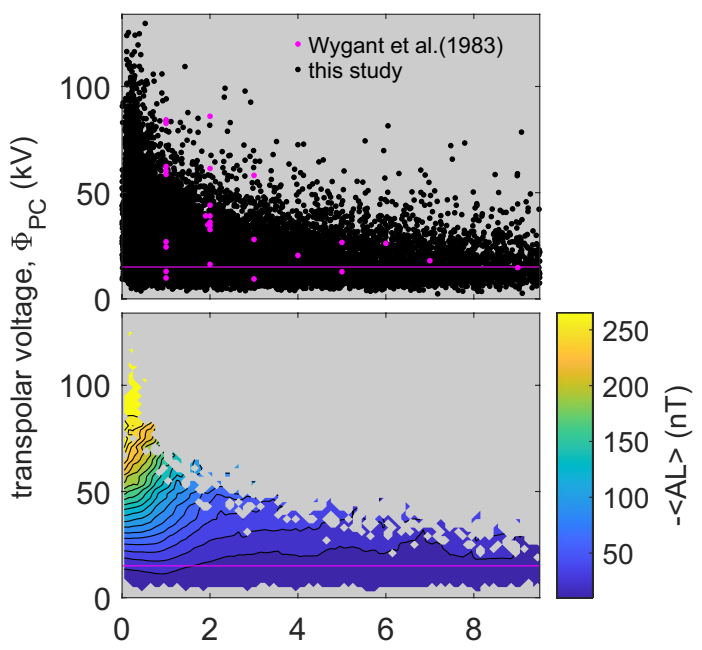

time after northward tuning, $\Delta \mathrm{t}=\mathrm{t}_{\mathrm{o}}-\mathrm{t}_{\mathrm{n}}$ (hrs)

Figure 10. Detail of Figure 9 at small times since the interplanetary magnetic field (IMF) turned northward, $\Delta t=\left(t_{0}-t_{\mathrm{n}}\right)$, where $t_{0}$ is the time of the $\Phi_{\mathrm{PC}}$ observation and $t_{\mathrm{n}}$ is the time at which the IMF turned northward. The black dots in the top panel form a scatter plot of the $\Phi_{\mathrm{PC}}$ data as a function of $\Delta t$ from the present survey. The mauve dots are the satellite $\Phi_{\mathrm{PC}}$ data from Wygant et al. (1983), which have been scaled to the radar values using the best-fit linear regression shown in part (c) of Figure A1. The lower panel shows contours of the mean $A L$ index for the data points of the present survey (and so is a contoured version of Figure $9 \mathrm{~b}$ for small $\Delta t$ ). their small data set is confirmed by our large survey. The lower panel shows the contours of mean $-A L$ in our survey and confirms the role of nightside reconnection invoked by the ECPC model explanation of the Wygant et al. plot.

\subsection{Effect of Solar Wind Dynamic Pressure, $p_{\mathrm{Sw}}$}

In this section, we investigate the effect of solar wind dynamic pressure $p_{\mathrm{SW}}$ on the magnetosphere. From Figure 6 , we use $p_{\mathrm{Sw}}$ values taken $\delta t=75 \mathrm{~min}$ before the corresponding $A L$ and $\Phi_{\mathrm{PC}}$ observation to allow for a propagation lag $\delta t$ through the magnetosheath from the nose of the magnetosphere to sufficient distances down the tail to squeeze the tail reconnection site and so modulate the tail reconnection voltage $\Phi_{\mathrm{N}}$. The analysis was also carried out for $\delta t=5 \mathrm{~min}$ appropriate for the propagation from the nose of the magnetosphere to the dayside magnetopause and $\delta t=120 \mathrm{~min}$ that gives the peak correlation between $p_{\mathrm{SW}}$ and $\Phi_{\mathrm{PC}}$. The autocorrelation function of $p_{\text {Sw }}$ only falls to 0.5 at a lag of $6 \mathrm{~h}$ and because of this great persistence in the $p_{\mathrm{Sw}}$ data series, essentially the same features as shown here were observed for all the three $\delta t$ values used.

Figure 11 looks at the dependence on IMF $B_{Z}$ and the solar wind dynamic pressure (normalized by the mean, i.e., $p_{\mathrm{Sw}} /\left\langle p_{\mathrm{SW}}\right\rangle$ ) of (top) the midlatitude am geomagnetic range index (Mayaud, 1980), (middle) the mean $-A L$ and (bottom) the mean transpolar voltage $\Phi_{\mathrm{PC}}$. In the left-hand panels, averages are given in bins that are $\Delta B_{Z}=0.5 \mathrm{nT}$ wide in IMF $B_{Z}$ and 0.1 wide in $p_{\mathrm{SW}} /<p_{\mathrm{SW}}>$. The right-hand panels show fitted contours to these data and highlight the gradients (but unlike the mean values contours cannot be plotted in areas where the data are sparse). For all the panels, values increase as we move to the left, that is, with increasingly southward IMF. This is seen at all $\left.p_{\mathrm{SW}} /<p_{\mathrm{SW}}\right\rangle$ values. All the parameters show an increase with $\left.p_{\mathrm{SW}} /<p_{\mathrm{SW}}\right\rangle$, at a given IMF $B_{Z}$ for $B_{Z}>0$ and for all the three parameters this increase decreases as the IMF becomes increasingly southward (i.e., the tilted contours become progressively more vertical). For the $a m$ index, we see clear increases with increasing $p_{\mathrm{Sw}}$ at all IMF $B_{Z}$, although they are weaker for more strongly southward IMF. This effect of $p_{\mathrm{SW}}$ on $a m$ has recently been identified and modeled by Lockwood, McWilliams, et al. (2020), Lockwood, Owens, et al. (2020), and Lockwood et al. (2021) as being the effect of $p_{\mathrm{Sw}}$ in squeezing the near-Earth tail. For both $-A L$ and $\Phi_{\mathrm{PC}}$, on the other hand, the contours become vertical for strongly southward IMF and the effect of enhanced $p_{\mathrm{Sw}}$ is no longer present. We infer $A L$ and $\Phi_{\mathrm{PC}}$ respond to increased $\Phi_{\mathrm{N}}$ caused by the squeezing effect of $p_{\mathrm{Sw}}$ on the magnetic shear across near-Earth cross tail current sheet, for northward IMF and for weakly southward IMF. From the studies of Lockwood, McWilliams, et al. (2020), Lockwood, Owens, et al. (2020), and Lockwood et al. (2021), we believe $a m$ also responds to the enhanced energy density stored in the tail lobes because of the same squeezing effect of $p_{\mathrm{SW}}$. Figure 12 confirms the trends to higher values at higher $p_{\mathrm{SW}}$ by showing the mean values, averaged over all IMF $B_{Z}$, with error bars of plus and minus one standard deviation: these are large because of the large variation introduced by $B_{Z}$. The upward trend is seen in all the three parameters but noticeably the gradient of the third-order polynomial fit decreases at larger $p_{\mathrm{Sw}}$ for both $A L$ and $\Phi_{\mathrm{PC}}$. The gray areas in Figure 12 are bounded by plus and minus 1-sigma error in the polynomial fit.

Figure $9 \mathrm{c}$ shows that the $p_{\mathrm{Sw}}$ effect does play a role in the behavior during northward IMF. This plot is the same as $9 \mathrm{a}$ and $9 \mathrm{~b}$ but shows the mean values of $p_{\mathrm{SW}}$ in the bins. It can be seen that the larger values of $\Phi_{\mathrm{PC}}$ at a given time since the IMF turned northward tend to be at larger $p_{\mathrm{SW}}$.

\subsection{A Sensitivity Study of the Effects of the Availability of Radar Echoes}

In the above sub-sections, all the plots shown are for the number of radar echoes $n_{\mathrm{e}}>n_{\min }=255$. We have also generated all the plots using all of the $9 n_{\min }$ values given by the colored lines in Figure 4 . The trends in 

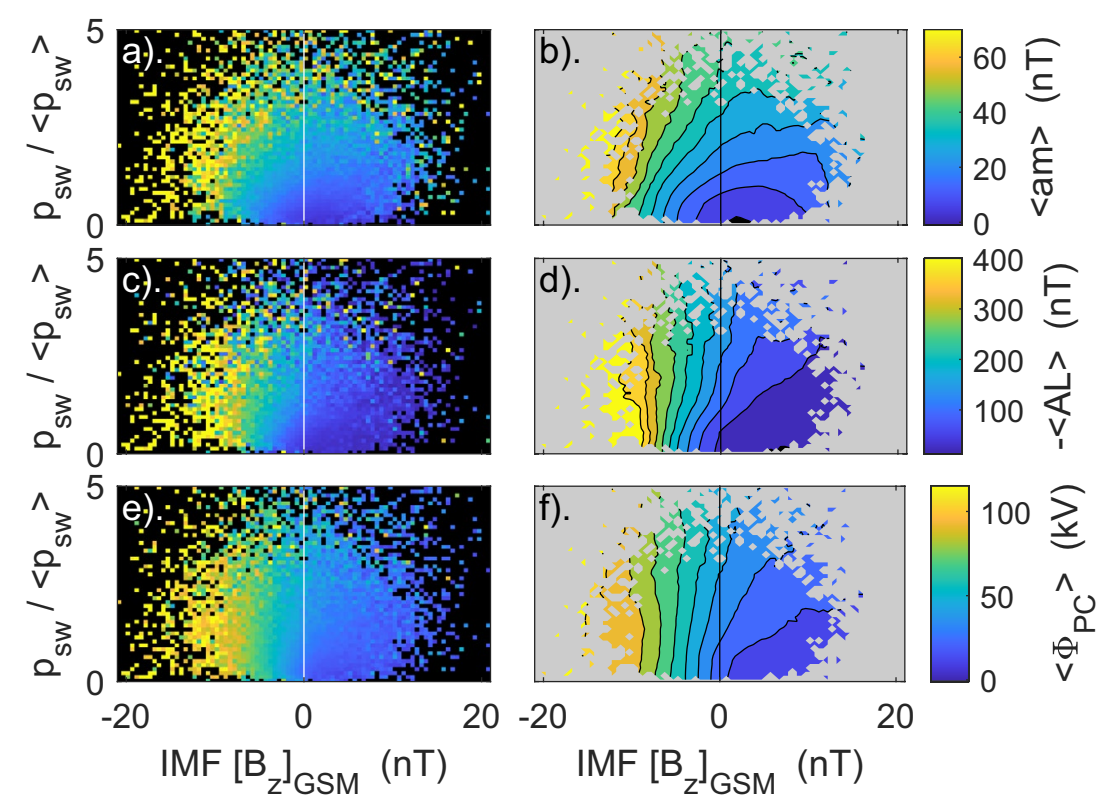

Figure 11. The left-hand plots show mean values in bins and the right-hand plots the same data fitted with contours. The top plots (a) and (b) are for the midlatitude am geomagnetic range index (Mayaud, 1980); the middle plots (c) and (d) are for the mean negative $A L$ index; and the bottom plots (e) and (f) are for the mean transpolar voltage $\Phi_{\mathrm{PC}}$. All are a function of the lagged north-south IMF component ( $B_{Z}$, defined as positive northward) in the GSM frame of reference and the normalized solar wind dynamic pressure, $p_{\mathrm{SW}} /<p_{\mathrm{SW}}>$, where $p_{\mathrm{SW}}=m_{\mathrm{SW}} N_{\mathrm{SW}} V_{\mathrm{SW}}^{2}$ is the mean ion mass, $m_{\mathrm{SW}}$ the number density and $V_{\mathrm{SW}}$ the speed of the solar wind and the normalizing factor $\left\langle p_{\mathrm{Sw}}\right\rangle$ is the mean for all data in the 1995-2020 period of this study. The $A L, \Phi_{\mathrm{PC}}$, and $p_{\mathrm{Sw}}$ are all 15-min boxcar running means of 1-min data whereas the $a m$ data are linearly interpolated to the time of the $\Phi_{\mathrm{PC}}$ sample from the raw 3-hourly am data. Bins are $\Delta B_{Z}=0.5 \mathrm{nT}$ wide in IMF $B_{Z}$ and 0.1 wide in $p_{\mathrm{SW}} /<p_{\mathrm{SW}}>$. Bins with no samples are shaded black in the left-hand panels and given areas of gray on the right where the data are too sparse for contours to be fitted. The $a m,-A L$, and $\Phi_{\mathrm{PC}}$ values used were for times of $\Phi_{\mathrm{PC}}$ samples that are based on $n_{\mathrm{e}}>255$ radar echoes.

all the plots are the same, the main effect being to change the absolute values in the means of $\Phi_{\mathrm{PC}}$. Figure 13 compares the variations of $\Phi_{\mathrm{PC}}$ with IMF $B_{Z}$ for the thresholds $n_{\min }$ of [100:100:900] (i.e., between 100 and 900 in steps of 100), shown in Figure 13b with that for $n_{\min }=255$ shown in Figure 13a. In Figure 13a, the mean values and standard deviations are given for each $B_{Z}$ bin as well as the sixth-order polynomial fit (solid line). In Figure 13b, only the polynomial fits are plotted to avoid overplotting the multiple cases. It can be seen that the same behavior is seen at all $n_{\min }$ values, the main difference being that $\Phi_{\mathrm{PC}}$ values are systematically higher for larger $n_{\min }$ at all values of IMF $B_{Z}$. This is expected because removal of values based on low numbers of echoes systematically removes low $\Phi_{\mathrm{PC}}$ samples, as shown by Figure 5 . We note that this effect is seen for both northward and southward IMF samples, except for the very largest (positive) $B_{Z}$ when the mean $\Phi_{\mathrm{PC}}$ is close to $25 \mathrm{kV}$, irrespective of the $n_{\min }$ used.

Figure 14 makes the equivalent comparisons of the average variations of $\Phi_{\mathrm{PC}}$ for $B_{Z}>0$ with time elapsed $\Delta t$ since the IMF turned northward. Again, the clear trend is to larger $\Phi_{\mathrm{PC}}$ at larger $n_{\min }$. However, this is not true for all $\Delta t$ as the effect declines in amplitude at $\Delta t>5 \mathrm{~h}$ and is not seen at all at $\Delta t>10 \mathrm{~h}$, such that at the largest positive $B_{Z}$ all $n_{\text {min }}$ thresholds give a near constant $\Phi_{\mathrm{PC}}$ of $15 \mathrm{kV}$.

We emphasize that all the plots presented in Sections 3.2-3.4 have been generated using all $9 n_{\min }$ thresholds of $n_{\mathrm{e}}$ used in Figures 4, 5,13 and 14. In every case, the form of the plot is essentially the same, the main effect being that there are fewer samples available and so the plots cover smaller ranges of the parameters as noise due to lack of samples becomes a greater issue in the tails of the distributions. 

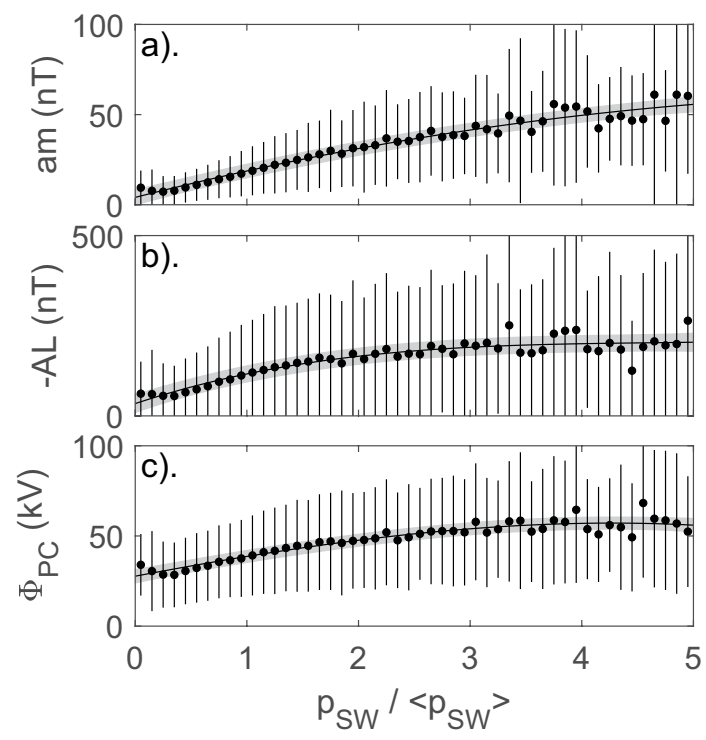

Figure 12. Mean values (with uncertainty bars of plus and minus one standard deviation) of (a) the am geomagnetic range index, (b) the negative $A L$ index, and (c) the transpolar voltage $\Phi_{\mathrm{PC}}$ as a function of the normalized solar wind dynamic pressure $p_{\mathrm{sw}} /\left\langle p_{\mathrm{sw}}\right\rangle$ in bins that are 0.1 wide in $\left.p_{\mathrm{sw}} /<p_{\mathrm{sw}}\right\rangle$. The black line is the best third-order polynomial fit to the mean values and the gray area around it is bound by plus and minus the 1-sigma error in the fit. The $a m,-A L$, and $\Phi_{\mathrm{PC}}$ values used were for times of $\Phi_{\mathrm{PC}}$ samples that are based on $n_{\mathrm{e}}>255$ radar echoes.

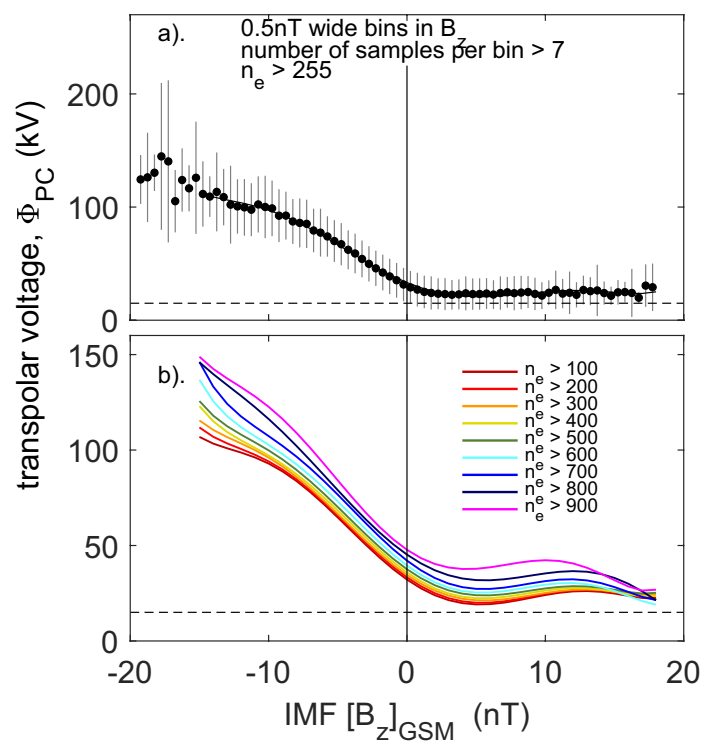

Figure 13. (a) Mean values (with uncertainty bars of plus and minus one standard deviation) of the transpolar voltage $\Phi_{\mathrm{PC}}$ as a function of interplanetary magnetic field (IMF) $B_{Z}$ (in the geocentric solar magnetospheric [GSM] frame of reference) in bins that are $\Delta B_{Z}=0.5 \mathrm{nT}$ wide for $\Phi_{\mathrm{PC}}$ samples that are based on $n_{\mathrm{e}}>255$ radar echoes. The solid line is a sixth-order polynomial fit to the mean values. (b) Analysis of the effect on part (a) of the threshold required for the number of radar echoes, $n_{\mathrm{e}}$. The colored lines are sixth-order polynomial fits to the mean values of $\Phi_{\mathrm{PC}}$ for $n_{\mathrm{e}}$ thresholds of $n_{\min }=$ [100:100:900] that were also used in Figures 4 and 5.

\section{Discussion and Conclusions}

\subsection{The Dependence of Transpolar Voltage on Magnetic Reconnection in Both the Magnetopause and the Cross-Tail Current Sheet}

We have regenerated two scatter plots that formed an important basis for the space physics community's understanding of magnetospheric and ionospheric convection. The plots of transpolar voltage as a function of the IMF $B_{Z}$ (for example, by Boyle et al., 1997; Cowley, 1984; Hairston et al., 1998; Reiff et al., 1981) were generated using typically less than 100 satellite passes. The plot by Wygant et al. (1983) of transpolar voltage as a function of time since the IMF was last southward was generated from just 28 data points. Here, we increase those numbers of data points by factors of over 1,000 using convection patterns derived from the SuperDARN array of ground-based coherent radars.

We have used the $A L$ auroral electrojet index to show that the scatter in these plots is well explained by the effect of the nightside voltage caused by reconnection in the cross-tail current sheet, as predicted by the ECPC model (Cowley \& Lockwood, 1992), and as was postulated in discussion and application of the model (e.g., Lockwood \& Cowley, 1992; Lockwood \& Morley, 2004; Lockwood et al., 2006; Milan, 2004; Milan et al., 2003, 2021). This has not been illustrated as clearly before now.

\subsection{Estimates of Voltage due to Viscous-Like Interaction Across the Magnetopause}

We have demonstrated that the residual transpolar voltage after a period of southward IMF decays away with time elapsed since the IMF has been northward. After about $24 \mathrm{~h}$, the voltage has decayed to $\Phi_{\mathrm{PC}} \approx 15 \mathrm{kV}$ and although in general $\Phi_{\mathrm{PC}}$ values are slightly sensitive to our choice of how many echoes are required $\left(n_{\mathrm{min}}\right)$ to yield a valid $\Phi_{\mathrm{PC}}$ estimate, we have shown that this is not true for this estimate of the residual $\Phi_{\mathrm{PC}}$ after long ( $\sim 1$ day) intervals of northward IMF. There are some points that should be noted about this value. From the above discussion, if both $\Phi_{\mathrm{N}}$ or $\Phi_{\mathrm{D}}$ could be considered to be zero at these times, then we get a maximum estimate of the viscously like voltage $\Phi_{\mathrm{V}}<\Phi_{\mathrm{PC}} \approx 15 \mathrm{kV}$.

Viscously driven flows, by definition, appear in the region of closed field lines on the flank of the magnetosphere called the LLBL (see Figure 1). One problem is defining what are closed field lines and Fuselier et al. (1999) have pointed out that some of the particle flux signatures traditionally used to identify closed field lines are actually best explained as open field lines. Mozer (1984) surveyed 24 LLBL crossings and found the voltage across the LLBL on one flank ranged between 0 and $16 \mathrm{kV}$, with an average of $3 \mathrm{kV}$. Mozer et al. (1994) surveyed 41 such crossings and found an average value of $4 \mathrm{kV}$. If such a voltage existed on both the flanks simultaneously, this implies a viscous voltage $\Phi_{\mathrm{V}}$ in the range $0-32 \mathrm{kV}$ with a mean value of $6-8 \mathrm{kV}$. These values are obtained by integrating the along-track electric field seen by magnetospheric spacecraft as they pass through the LLBL. Hapgood and Lockwood (1993) pointed out that an assumption in these measurements is that the LLBL is stationary and that the satellite moves through it so that the LLBL thickness is the speed of the satellite times the time it resides in the LLBL. However, in general, a better approximation would be that the satellite be considered 


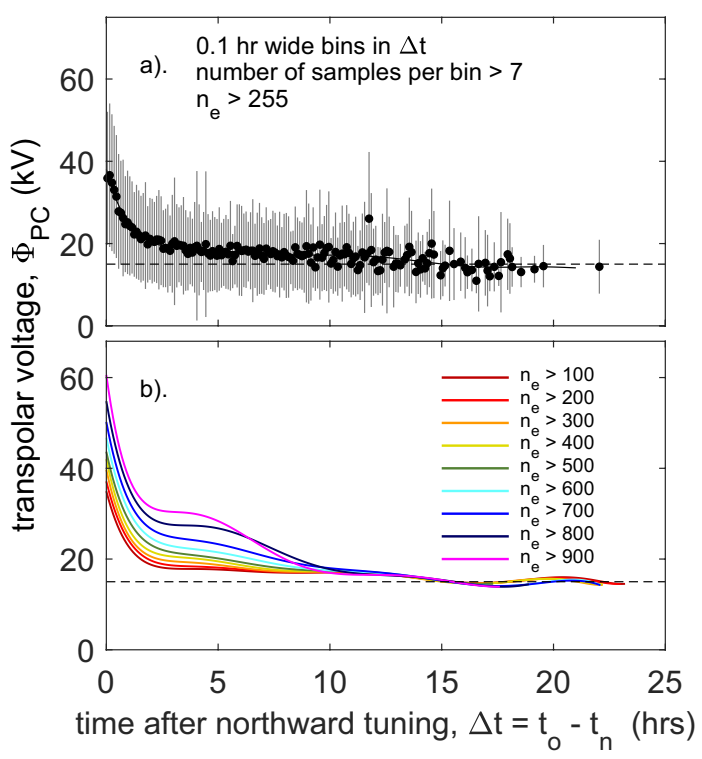

Figure 14. (a) Mean values (with uncertainty bars of plus and minus one standard deviation) of the transpolar voltage $\Phi_{\mathrm{PC}}$ during northward interplanetary magnetic field (IMF) as a function of time since the lagged IMF turned northward, $\Delta t=\left(t_{0}-t_{\mathrm{n}}\right)$ in bins that are $0.1 \mathrm{~h}$ wide: $t_{0}$ is the time of the $\Phi_{\mathrm{PC}}$ observation and $t_{\mathrm{n}}$ is the time at which the IMF turned northward. $\Phi_{\mathrm{PC}}$ samples are based on $n_{\mathrm{e}}>255$ radar echoes. The solid line is a sixth-order polynomial fit to the mean values. (b) Analysis of the effect on part (a) of the threshold required for the number of radar echoes, $n_{\mathrm{e}}$. The colored lines are sixth-order polynomial fits to the mean values of $\Phi_{\mathrm{PC}}$ for $n_{\mathrm{e}}$ thresholds of [100:100:900] that were also used in Figures 4, 5 and 13 . stationary and the boundary moves over it and that large estimates in LLBL thickness and $\Phi_{\mathrm{V}}$ can arise from a boundary that happens to be moving with the craft. They used plasma characteristics in the LLBL to show that for some cases of apparently large viscously driven voltage the true value was, in fact, only about $3 \mathrm{kV}$ on one flank: if the same applied on the other flank $\Phi_{\mathrm{V}}$ would be $6 \mathrm{kV}$. In theory, we should be able to use multi-spacecraft missions that pass through the LLBL to resolve boundary motions and compute LLBL thickness and voltage. Such missions include Active Magnetospheric Particle Tracer Explorer (AMPTE), Cluster, Magnetospheric Multiscale Mission (MMS) and Time History of Events and Macroscale Interactions during Substorms (THEMIS). Although we can find several examples of the use of these spacecraft to determine LLBL thickness, a literature search has not revealed any further estimates of LLBL voltage. However, we note that Lockwood and Hapgood (1997) did use the AMPTE-IRM and AMPTE-UKS pair to show that the analysis of Hapgood and Lockwood (1993) was correct.

A detailed study of convection reversals in the ionosphere near dawn and dusk indicates that sometimes the plasma motion across them exceeds the motion of the boundary, implying they are not just moving adiaroic boundaries and there is a genuinely viscous-like process at work (Chen \& Heelis, 2018; Lockwood et al., 1988); however, in such cases, the true boundary motion and orientation are very difficult to determine accurately and uncertainties are large making accurate determination of $\Phi_{\mathrm{V}}$ by integrating along the boundary almost impossible. Newell et al. (1991) and Sundberg et al. (2008) used LEO observations of electric fields and particle precipitations to infer the voltage across the low-altitude footprint of the LLBL and find values mainly below $10 \mathrm{kV}$ with a few values over $20 \mathrm{kV}$. There are two problems with this which may explain the larger estimates of $\Phi_{\mathrm{V}}$. First, the identification of closed LLBL field lines from the particle precipitations is not definitive. Second, the ECPC model predicts that antisunward flow on closed field lines in the ionospheric projection of the LLBL can be generated by nightside reconnection and polar cap contraction because the CRB can be shifted from the open-closed field line boundary by the conductivity distribution in the ionosphere.

From the above, a mean value of $\Phi_{\mathrm{V}}$ of around $8 \mathrm{kV}$ is appropriate and so the estimate of $\Phi_{\mathrm{V}} \leq 15 \mathrm{kV}$ derived here from Figure 14, is somewhat higher than we would expect for an average value of past estimates. However, we stress here that this is a maximum value for $\Phi_{\mathrm{V}}$ because it is derived assuming $\Phi_{\mathrm{D}}=0$ and $\Phi_{\mathrm{N}}=0$ with lobe reconnection voltages lower than $\Phi_{\mathrm{V}}$. There are reasons to believe that none of these assumptions are valid. First, it has been shown from outward fluxes of ionospheric ion species that opening of field lines continues between the magnetic cusps at a low level even when the IMF points northward (Chandler et al., 1999; Fuselier et al., 2000) and observations of simultaneous "double" cusps have been interpreted as subsolar reconnection continuing even though the IMF is northward and lobe reconnection is simultaneously taking place (Lockwood \& Moen, 1999; Lockwood et al., 2003; Pitout et al., 2002). Thus far, we have only a limited number of such observations and so cannot say how common this situation is. Hence, although $\Phi_{\mathrm{D}}$ is small during northward IMF, it may be larger than zero some or all of the time. Second, as pointed out by Lockwood (2019), the tail lobes have never been seen to vanish, no matter how long the IMF remains northward. This means there is always a cross-tail current sheet with magnetic shear across it at which we would expect nightside reconnection to occur, even if the resulting $\Phi_{\mathrm{N}}$ is small. Third Wilder et al. (2008) use SuperDARN data to show that the lobe reconnection voltages in the ionosphere saturates at about $15-20 \mathrm{kV}$ and hence the voltages seen at large times since the IMF turned northward are likely to be caused by lobe reconnection than by viscous-like interaction.

Our definition of $\Phi_{\mathrm{PC}}$ means that a lobe reconnection voltage $\Phi_{\mathrm{L}}$ would, if large enough either increase (the "hybrid" case) or set the value of $\Phi_{\mathrm{PC}}$ (the lobe-dominated case) such that its effect in the ionosphere 
exceeded $\Phi_{\mathrm{V}}$ (see Section 1.1). Figure 7 shows that northward IMF $\Phi_{\mathrm{PC}}$ increases up to $15 \mathrm{kV}$ as the IMF approaches its largest positive values, which is a behavior expected of $\Phi_{\mathrm{L}}$ rather than $\Phi_{\mathrm{V}}$. Hence, the $15 \mathrm{kV}$ is consistent with being a "lobe dominated" $\Phi_{\mathrm{PC}}$ value set by lobe reconnection and not a "conventional" or "hybrid" viscous-like voltage to which $\Phi_{\mathrm{V}}$ could have contributed. As a consequence, we must treat $15 \mathrm{kV}$ as an upper limit to the average value of $\Phi_{\mathrm{V}}$ and it is very likely to be very considerably lower than this.

\subsection{The Effect of Dynamic Pressure}

There are physical reasons to expect both $\Phi_{\mathrm{D}}$ and $\Phi_{\mathrm{N}}$ to be increased by increased solar wind dynamic pressure $p_{\mathrm{SW}}$. In both the cases, the compression brought about by greater $p_{\mathrm{SW}}$ should increase the magnetic shear across the current sheet and so enhance the reconnection rate. One caveat to this idea is that the nightside reconnection must be taking place at a GSM X-coordinate at which the tail is still flaring (i.e., the radius increases with increasingly negative $\mathrm{X}$ ) and so the dynamic pressure can squeeze the tail lobe and so increase the lobe field (Caan et al., 1973) and the cross-tail current (Lockwood, 2013). At larger $-X$ coordinates, further down the tail, the tail radius asymptotically reaches its maximum value and the component of the dynamic pressure perpendicular to the magnetopause falls to zero: in this case, the lobe field and magnetic shear across the cross-tail current sheet are set by the static pressure in the interplanetary medium.

Using the am geomagnetic index as a proxy indicator of magnetopause reconnection, Scurry and Russell (1991) inferred statistically that dayside reconnection voltage $\Phi_{\mathrm{D}}$ was indeed enhanced by increased $p_{\text {sw. }}$. However, much of the evidence for such an effect comes from transient responses to individual events in which $p_{\text {Sw }}$ increases suddenly (e.g., Boudouridis et al., 2007). The problem with these events is that there will be a number of transient responses, of which the effect of $p_{\mathrm{SW}}$ on $\Phi_{\mathrm{D}}$ is one and isolating just that one effect is difficult.

An important effect of $p_{\mathrm{SW}}$ on the tail was demonstrated directly by Karlsson et al. (2000) who showed that near-Earth tail energy content was reduced if $p_{\mathrm{Sw}}$ decreased and that such sudden decreases caused quenching of any substorm expansion that had recently begun. This strongly suggests reduced $p_{\mathrm{Sw}}$ can reduce the nightside voltage, $\Phi_{\mathrm{N}}$. Conversely, increases in $p_{\mathrm{SW}}$ have been seen to trigger onsets of full substorm expansion phases (Kokubun et al., 1977; Schieldge \& Siscoe, 1970; Yue et al., 2010) and have been identified as a cause of a rise in $\Phi_{N}$ (Boudouridis, Lyons, et al., 2008). In some cases, the rise in $\Phi_{N}$ has been inferred from a loss of open flux as aurora expands into what appears to be open flux (Hubert, Palmroth, et al., 2006).

Various observational studies suggest that increases in $p_{\mathrm{SW}}$ cause enhanced general magnetospheric convection and field-aligned current systems as well as enhanced geomagnetic activity (e.g., Boudouridis, Zesta, et al., 2008; Hubert, Milan, et al., 2006; Lee et al., 2004; Lukianova, 2003; Stauning \& Troshichev, 2008). This phenomenon has been modeled using global MHD models of the magnetosphere as being caused by rises in both $\Phi_{\mathrm{D}}$ and $\Phi_{\mathrm{N}}$ (Connor et al., 2014; Lockwood, Owens, et al., 2020; Ober et al., 2006; Palmroth et al., 2004).

Figure 15 looks at the implications for any influence of $p_{\mathrm{SW}}$ on $\Phi_{\mathrm{D}}$ and $\Phi_{\mathrm{N}}$ of the correlations between $p_{\mathrm{SW}}$ and the auroral electrojet indices for both northward and southward IMF. It also compares the correlograms with those for $p_{\mathrm{Sw}}$ and $\Phi_{\mathrm{PC}}$ for northward and southward IMF that were shown in Figure 6 . The blue and orange lines are for $A U$ and $A L$, respectively, for southward IMF $\left(B_{Z}<0\right)$. Both show a rapid response, although the correlation does not decay away for large positive lags as quickly for $A U$ as it does for $A L$. Note, that correlations are lower for the southward IMF data than for northward IMF (shown by the mauve and green lines) because the controlling influence of IMF $B_{Z}$ is much greater for southward IMF. The mauve and green lines are for $A U$ and $A L$, respectively, and for northward IMF we see that $A L$ responds to $p_{\mathrm{SW}}$ after a long lag, consistent with the squeezing of the tail by increased $p_{\mathrm{Sw}}$ increasing $\Phi_{\mathrm{N}}$. From the peak correlation, this appears to be a relatively weak effect compared to the peaks for $A U$ : however, it must be remembered that the lag for the dayside effect is short and much less variable than for any effect on the nightside and so we should expect a broad, but relatively low, peak for the effect on $A L$. Also, note the peak for $A U$ at short lags for northward IMF implies that the dayside reconnection is not only enhanced by increased $p_{\mathrm{SW}}$ when the IMF is southward, but that it may still present and be enhanced by $p_{\mathrm{SW}}$ when the IMF is northward. Finch et al. (2008) and Lockwood, McWilliams, et al. (2020) found that the effect of $p_{\mathrm{SW}}$ on midlatitude range indices was through the nightside substorm current wedge. These authors also showed that the effect was associated with $\Phi_{\mathrm{N}}$ and was the origin of the equinoctial time-of-day/time-of-year pattern 


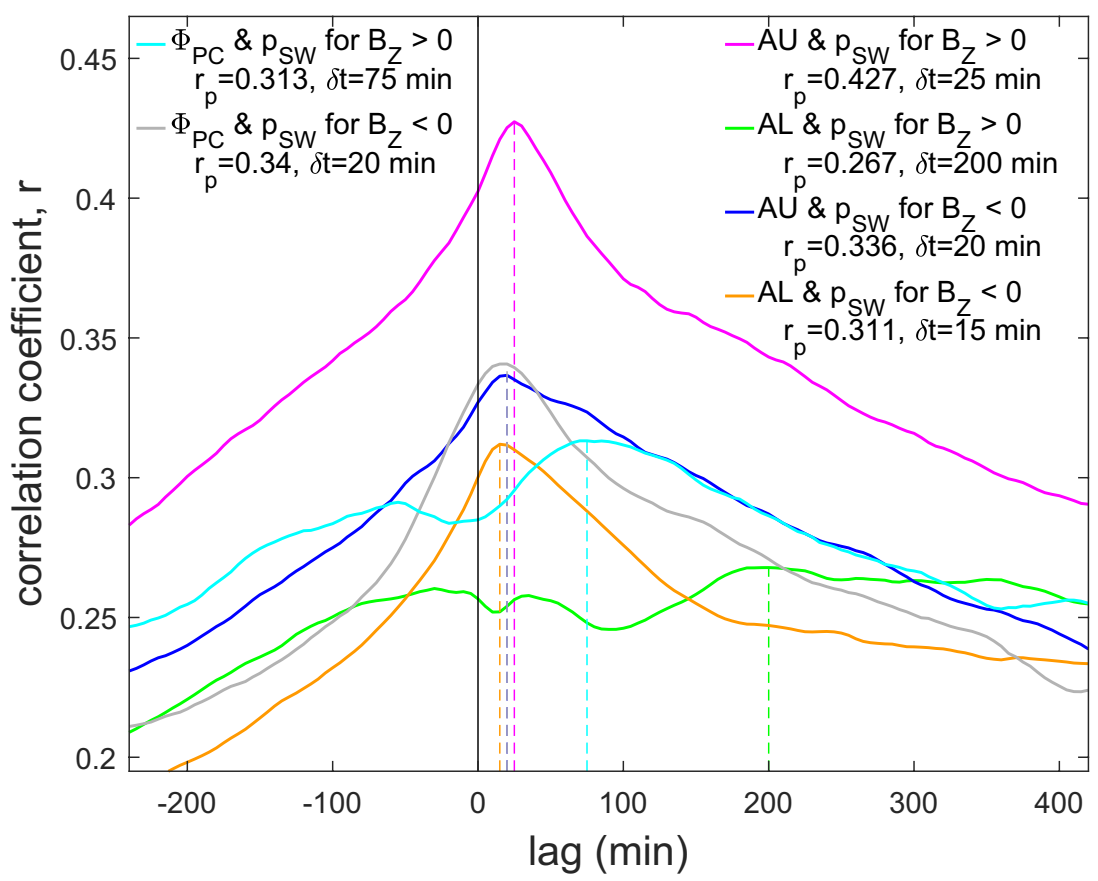

Figure 15. Lag correlograms for auroral electrojet indices with solar wind dynamic pressure: (mauve) for $A U$ and $p_{\mathrm{Sw}}$ for interplanetary magnetic field (IMF) $B_{Z}>0$ (in the geocentric solar magnetospheric [GSM] frame); (green) for $A L$ and $p_{\mathrm{SW}}$ for IMF $B_{Z}>0$; (blue) for $A U$ and $p_{\mathrm{Sw}}$ for IMF $B_{Z}<0$; and (orange) for $A L$ and $p_{\mathrm{SW}}$ for IMF $B_{Z}<0$. In each case, the first parameter of the pair has been lagged with respect to the second by the lag given by the $x$-axis. The vertical dashed lines are at the lag $\delta t$ yielding maximum $r, r_{p}$, and the values for $\delta t$ and $r_{p}$ are given for each case. The cyan and gray lines are the corresponding lag correlograms for the transpolar voltage $\Phi_{\mathrm{PC}}$ and $p_{\mathrm{SW}}$ for IMF $B_{Z}>0$ and IMF $B_{Z}<0$, respectively.

in geomagnetic activity through the effect of the dipole tilt. The modeling analysis of Lockwood, Owens, et al. (2020) found the influence of $p_{\mathrm{Sw}}$ through both $\Phi_{\mathrm{N}}$ and the energy stored in the tail lobe. The results presented here show an effect of $p_{\mathrm{SW}}$ on $\Phi_{\mathrm{PC}}$, but that the effect is smaller than for am: this indicates that the effect of energy stored in the tail may be a larger factor for midlatitude range indices such as am.

Since submitting the present paper, an article by Boudouridis et al. (2021) has been published, presenting an observation and modeling case study on enhancements in $\Phi_{\mathrm{D}}$ and $\Phi_{\mathrm{N}}$, and hence $\Phi_{\mathrm{PC}}$, induced by enhanced $p_{\mathrm{SW}}$. As mentioned above, the studies of transient responses do not necessarily reveal the dependence of $\Phi_{\mathrm{D}}$ and $\Phi_{\mathrm{N}}$, and hence $\Phi_{\mathrm{PC}}$, on $p_{\mathrm{SW}}$ because of other transient responses although they do show a connection. We here have shown that there is a connection on a statistical basis. One potential problem is that $p_{\text {Sw }}$ has many parameters in common with the power input into the magnetosphere (Lockwood et al., 2019a), but Lockwood, McWilliams, et al. (2020), Lockwood, Owens, et al. (2020), and Lockwood et al. (2021) have demonstrated that it has a separate and distinct influence on the am midlatitude, range geomagnetic activity index. We here have demonstrated that $p_{\text {sw }}$ has a similar influence on the nightside auroral $A L$ index and the transpolar voltage $\Phi_{\mathrm{PC}}$.

\section{Appendix A: Analysis and Calibration of the Radar Data}

The Super Dual Auroral Radar Network (SuperDARN) data used here were processed at the Institute of Space and Atmospheric Studies, University of Saskatchewan, using the SuperDARN Radar Software Toolkit (RST) 4.3 (2019) developed and maintained by the SuperDARN Data Analysis Working Group and available from the Github URL https://zenodo.org/record/3401622\#.YNuIbUwo-1k.

The reference for this version of the RST is: SuperDARN Data Analysis Working Group. Participating members; Thomas, E. G.; Sterne, K. T.; Shepherd, S. G.; Kotyk, K.; Schmidt, M. T.; Ponomarenko, P. V.; Bland, 


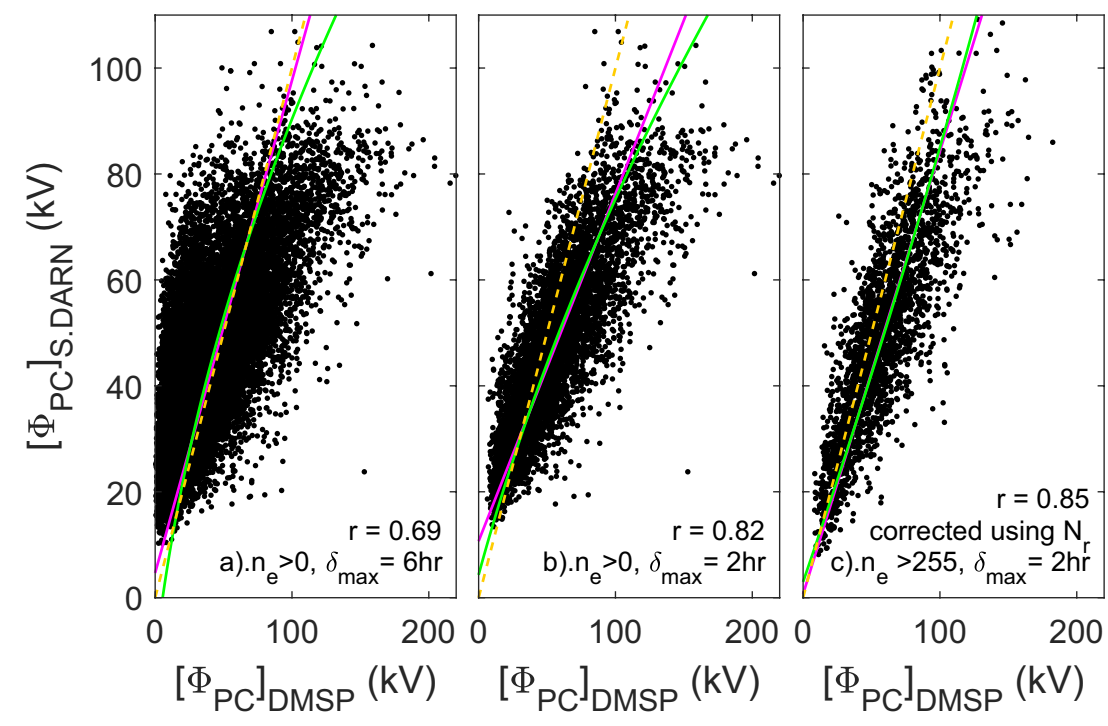

Figure A1. Comparisons of simultaneous (within $30 \mathrm{~min}$ ) transpolar voltage measurements by the Super Dual Auroral Radar Network (SuperDARN) radars, $\left[\Phi_{\text {PC }}\right]_{\text {S.DARN }}$, and from Defense Meteorological Satellite Program (DMSP) satellite passes, $\left[\Phi_{\mathrm{PC}}\right]_{\mathrm{DMSP}}$. The scatter plot in (a) is for all data, irrespective of how many radar Doppler shift measurements contributed to the SuperDARN values and the Magnetic Local Time separation from the maximum and minimum and minimum potential of the SuperDARN pattern ( $\delta$ values) of the DMSP intersections of the convection reversal boundary (CRB). In (b), the derived stringent criterion for the MLT of the DMSP intersections of the CRB $\left(\delta \leq \delta_{\max }=2 \mathrm{~h}\right)$ has been applied. In (c), the same restriction is applied to the DMSP passes and the number of radar data points, $n_{\mathrm{e}}$ must exceed 255 . On all the three plots, the mauve line is the best linear regression, the green line the second-order polynomial fit, and the orange dashed line the ideal agreement $\left(\left[\Phi_{\mathrm{PC}}\right]_{\mathrm{S} . \mathrm{DARN}}=\left[\Phi_{\mathrm{PC}}\right]_{\mathrm{DMSP}}\right)$. The correlation coefficient, $r$, and the r.m.s. deviation of the two data sets, $\Delta$, is given in each case. The number of data points in (a), (b), and (c) are 16,714, 6,023, and 2,468, respectively.

E. C.; Walach, M.-T.; Reimer, A. S.; Burrell, A. G.; Billett, D. D. (2019), SuperDARN Radar Software Toolkit (RST) 4.3, https://doi.org/10.5281/zenodo/3401622.

To allow reproduction of the data set, note that all the RST (version 4.3) defaults were used to create the potential maps, except the following:

1.fitacf-version 3.0 was used instead of fitacf-version 2.5

2.-tl 60 (scan time $60 \mathrm{~s}$ )

3.-c (concatenate grid files)

4.-minrng 10 (include data from minimum range gate 10)

5.use -cn a, b, c, d for channel fitacf files (a, b, c, d in the filename), or -cn_fic A, b for fitacfs with twofsound for channel 0 and 1 for $A$ and channel 2 for B

6.-xtd for extra variable spectral width and SNR

7.-stime 00:00 to give start time at 00:00

8.-vemax 10000 to exclude any data above velocity value of $10,000 \mathrm{~ms}^{-1}$

9.-1 50 to set map minimum latitude to $50^{\circ}$

10.-if OMNI.txt to use OMNI data set to drive re-analysis model

11.-d 00:10 for 10 min delay on the input OMNI data. Note that the results were not sensitive to this value and Figure 6 of the main paper shows that the observed lag between $\Phi_{\mathrm{PC}}$ and IMF $B_{Z}$ is $20 \mathrm{~min}$ and set by the observed radar Doppler shifts and not the model

12.-o 8 for harmonic order 8

13.-d 1 for low doping level. The doping level sets the relative weight given to the model compared to the data and can be set to light, medium and heavy. As we wish the maps to be strongly data-driven, we have set the model doping to light

Figure A1 presents an overview plot of the comparisons between SuperDARN and Defense Meteorological Satellite Program (DMSP) transpolar voltages (respectively $\left[\Phi_{\mathrm{PC}}\right]_{\text {S.DARN }}$ and $\left[\Phi_{\mathrm{PC}}\right]_{\mathrm{DMSP}}$ ) referred to in the text 
(The full analysis will appear in the paper Lockwood, M., K.A. McWilliams, and M.R. Hairston, Semiannual and Universal Time variations in magnetospheric convection: 1. Transpolar Voltage Data, to be submitted to J. Geophys. Res.). These comparisons are for data from 2001 and 2002 and are for dawn-to-dusk DMSP passes only and consider the effects of both the proximity of the satellite path of the diameter of the polar cap giving the transpolar voltage in the SuperDARN data (quantified by the parameter $\delta_{\max }$ ) and the number of echoes, $n_{\mathrm{e}}$ involved in computing $\left[\Phi_{\mathrm{PC}}\right]_{\text {S.DARN }}$.

\section{Acknowledgments}

The authors acknowledge the use of data from the SuperDARN project. SuperDARN is a collection of radars funded by national scientific funding agencies of Australia, Canada, China, France, Italy, Japan, Norway, South Africa, United Kingdom, and the United States of America. The work presented in this paper was supported by a number of grants. Mike Lockwood is supported by STFC consolidated grant number ST/M000885/1 and by the SWIGS NERC Directed Highlight Topic Grant number NE/P016928/1/. Funding for KAM at the University of Saskatchewan was provided by the Canadian Foundation for Innovation (CFI), the Province of Saskatchewan, and a Discovery Grant from the Natural Sciences and Engineering Research Council (NSERC) of Canada. Initial work by Kathryn A. McWilliams for this paper was carried out at the University of Reading on sabbatical leave from the University of Saskatchewan. The authors thank Evan Thomas, Kevin Sterne, Simon Shepherd, Keith Kotyk, Marina Schmidt, Pasha Ponomarenko, Emma Bland, Maria-Theresia Walach, Ashton Reimer, Angeline Burrell, and Daniel Billett for the SuperDARN radar processing toolkit used to analyze the radar data. The authors are also grateful to the staff of: the Space Physics Data Facility, NASA/Goddard Space Flight Center, who prepared and made available the OMNI2 data set used: these interplanetary data were downloaded from http://omniweb.gsfc.nasa.gov/ ow.html; the World Data Center for Geomagnetism, Kyoto who generate and make available the $A L$ index from http://wdc.kugi.kyoto-u.ac.jp/aeasy/ index.html and the staff of L'École et Observatoire des Sciences de la Terre (EOST), a joint project of the University of Strasbourg and the French National Center for Scientific Research (CNRS) and the International Service of Geomagnetic Indices (ISGI) for making the am index data available from http://isgi. unistra.fr/data_download.php.

\section{References}

Aikio, A., Pitkänen, T., Honkonen, I., Palmroth, M., \& Amm, O. (2013). IMF effect on the polar cap contraction and expansion during a period of substorms. Annales Geophysicae, 31, 1021-1034. https://doi.org/10.5194/angeo-31-1021-2013

Baker, D. N., Klimas, A. J., Vassiliadis, D., Pulkkinen, T. I., \& McPherron, R. L. (1997). Re-examination of driven and unloading aspects of magnetospheric substorms. Journal of Geophysical Research, 102(A4), 7169-7177. https://doi.org/10.1029/96JA02627

Baker, D. N., Zwickl, R. D., Bame, S. J., Hones, E. W., Tsurutani, B. T., Smith, E. J., \& Akasofu, S. -I. (1983). An ISEE 3 high time resolution study of interplanetary parameter correlations with magnetospheric activity. Journal of Geophysical Research, 88(A8), 6230-6242. https://doi.org/10.1029/JA088iA08p06230

Birn, J., Hones, E. W., Craven, J. D., Frank, L. A., Elphinstone, R. D., \& Stern, D. P. (1991). On open and closed field line regions in Tsyganenko's field model and their possible associations with horse collar auroras. Journal of Geophysical Research, 96(A3), 3811-3817. https://doi.org/10.1029/90JA02124

Boudouridis, A., Connor, H. K., Lummerzheim, D., Ridley, A. J., \& Zesta, E. (2021). Changes in the magnetic field topology and the dayside/nightside reconnection rates in response to a solar wind dynamic pressure front: A case study. Journal of Geophysical Research: Space Physics, 126, e2020JA028768. https://doi.org/10.1029/2020JA028768

Boudouridis, A., Lyons, L. R., Zesta, E., \& Ruohoniemi, J. M. (2007). Dayside reconnection enhancement resulting from a solar wind dynamic pressure increase. Journal of Geophysical Research, 112, A06201. https://doi.org/10.1029/2006JA012141

Boudouridis, A., Lyons, L. R., Zesta, E., Ruohoniemi, J. M., \& Lummerzheim, D. (2008). Nightside flow enhancement associated with solar wind dynamic pressure driven reconnection. Journal of Geophysical Research, 113, A12211. https://doi.org/10.1029/2008JA013489

Boudouridis, A., Zesta, E., Lyons, L. R., Anderson, P. C., \& Ridley, A. J. (2008). Temporal evolution of the transpolar potential after a sharp enhancement in solar wind dynamic pressure. Geophysical Research Letters, 35, L02101. https://doi.org/10.1029/2007GL031766

Boyle, C. B., Reiff, P. H., \& Hairston, M. R. (1997). Empirical polar cap potentials. Journal of Geophysical Research, 102(A1), 111-125. https://doi.org/10.1029/96JA01742

Bristow, W. A., Greenwald, R. A., Shepherd, S. G., \& Hughes, J. M. (2004). On the observed variability of the cross-polar cap potential. Journal of Geophysical Research, 109, A02203. https://doi.org/10.1029/2003JA010206

Browett, S. D., Fear, R. C., Grocott, A., \& Milan, S. E. (2017). Timescales for the penetration of IMF By into the Earth's magnetotail. Journal of Geophysical Research: Space Physics, 122, 579-593. https://doi.org/10.1002/2016JA023198

Caan, M. N., McPherron, R. L., \& Russell, C. T. (1973). Solar wind and substorm-related changes in the lobes of the geomagnetic tail. Journal of Geophysical Research, 78(34), 8087-8096. https://doi.org/10.1029/ja078i034p08087

Chandler, M. O., Fuselier, S. A., Lockwood, M., \& Moore, T. E. (1999). Evidence of component magnetic merging equatorward of the cusp. Journal of Geophysical Research, 104, 22623-22648. https://doi.org/10.1029/1999JA900175

Chen, Y.-J., \& Heelis, R. A. (2018). Motions of the convection reversal boundary and local plasma in the high-latitude ionosphere. Journal of Geophysical Research: Space Physics, 123, 2953-2963. https://doi.org/10.1002/2017JA024934

Chisham, G., Lester, M., Milan, S. E., Freeman, M. P., Bristow, W. A., Grocott, A., et al. (2007). A decade of the Super Dual Auroral Radar Network (SuperDARN): Scientific achievements, new techniques and future directions. Surveys in Geophysics, 28(1), 33-109. https:// doi.org/10.1007/s10712-007-9017-8

Connor, H. K., Zesta, E., Ober, D. M., \& Raeder, J. (2014). The relation between transpolar potential and reconnection rates during sudden enhancement of solar wind dynamic pressure: OpenGGCM-CTIM results. Journal of Geophysical Research: Space Physics, 119, 3411-3429. https://doi.org/10.1002/2013JA019728

Consolini, G., \& De Michelis, P. (2005). Local intermittency measure analysis of AE index: The directly driven and unloading component. Geophysical Research Letters, 32, L05101. https://doi.org/10.1029/2004GL022063

Cousins, E. D. P., Matsuo, T., \& Richmond, A. D. (2013). SuperDARN assimilative mapping. Journal of Geophysical Research: Space Physics, 118, 7954-7962. https://doi.org/10.1002/2013JA019321

Cowley, S. W. H. (1982). The causes of convection in the Earth's magnetosphere: A review of developments during the IMS. Reviews of Geophysics, 20(3), 531-565. https://doi.org/10.1029/RG020i003p00531

Cowley, S. W. H. (1984). Solar wind control of magnetospheric convection. In B. Battrick \& E. J. Rolfe (Eds.), Achievements of the International Magnetospheric Study (IMS), Proceedings of an International Symposium, held 26-28 June, 1984 in Graz, Austria. European Space Agency Special Publication, ESA-SP-217, (pp. 483-494). Paris: European Space Agency. ISSN 0379-6566.

Cowley, S. W. H., Freeman, M. P., Lockwood, M., \& Smith, M. F. (1991). The ionospheric signature of flux transfer events. In C. I. Barron (Ed.), CLUSTER—Dayside polar cusp, European Space Agency Special Publication, ESA-SP-330 (pp. 105-112). Paris: European Space Agency.

Cowley, S. W. H., \& Lockwood, M. (1992). Excitation and decay of solar-wind driven flows in the magnetosphere-ionosphere system. Annales Geophysicae, 10, 103-115.

Cowley, S. W. H., Morelli, J. P., \& Lockwood, M. (1991). Dependence of convective flows and particle precipitation in the high-latitude dayside ionosphere on the X and Y components of the interplanetary magnetic field. Journal of Geophysical Research, 96, 5557-5564. https://doi.org/10.1029/90JA02063

Davis, T. N., \& Sugiura, M. (1966). Auroral electrojet activity index AE and its universal time variations. Journal of Geophysical Research, 71(3), 785-801. https://doi.org/10.1029/JZ071i003p00785 
DeJong, A. D., Ridley, A. J., \& Clauer, C. R. (2008). Balanced reconnection intervals: Four case studies. Annales Geophysicae, 26, 3897-3912. https://doi.org/10.5194/angeo-26-3897-2008

Drayton, R. A., Koustov, A. V., Hairston, M. R., \& Villain, J.-P. (2005). Comparison of DMSP cross-track ion-drifts and SuperDARN line-ofsight velocities. Annales Geophysicae, 23(7), 2479-2486. https://doi.org/10.5194/angeo-23-2479-2005

Echer, E., Korth, A., Bolzan, M. J. A., \& Friedel, R. H. W. (2017). Global geomagnetic responses to the IMF $B_{\mathrm{z}}$ fluctuations during the September/October 2003 high-speed stream intervals. Annales Geophysicae, 35(4), 853-868. https://doi.org/10.5194/angeo-35-853-2017

Etemadi, A., Cowley, S. W. H., Lockwood, M., Bromage, B. J. I., Willis, D. M., \& Lühr, H. (1988). The dependence of high-latitude dayside ionospheric flows on the north-south component of the IMF: A high time resolution correlation analysis using EISCAT "POLAR" and AMPTE UKS and IRM data. Planetary and Space Science, 36, 471-498. https://doi.org/10.1016/0032-0633(88)90107-9

Farrugia, C. J., Gratton, F. T., \& Torbert, R. B. (2001). Viscous-type processes in the solar wind-magnetosphere interaction. Space Science Reviews, 95, 443-456. https://doi.org/10.1023/A:1005288703357

Finch, I. D., Lockwood, M., \& Rouillard, A. P. (2008). The effects of solar wind magnetosphere coupling recorded at different geomagnetic latitudes: Separation of directly-driven and storage/release systems. Geophysical Research Letters, 35, L21105. https://doi. org/10.1029/2008GL035399

Fuselier, S. A., Lockwood, M., Onsager, T. G., \& Peterson, W. K. (1999). The source population for the cusp and cleft/LLBL for southward IMF. Geophysical Research Letters, 26, 1665-1669. https://doi.org/10.1029/1999GL900354

Fuselier, S. A., Trattner, K. J., \& Petrinec, S. M. (2000). Cusp observations of high- and low-latitude reconnection for northward interplanetary magnetic field. Journal of Geophysical Research, 105(A1), 253-266. https://doi.org/10.1029/1999JA900422

Gao, Y. (2012). Comparing the cross polar cap potentials measured by SuperDARN and AMIE during saturation intervals. Journal of Geophysical Research, 117, A08325. https://doi.org/10.1029/2012JA017690

Gordeev, E. I., Sergeev, V. A., Pulkkinen, T. I., \& Palmroth, M. (2011). Contribution of magnetotail reconnection to the cross-polar cap electric potential drop. Journal of Geophysical Research, 116, A08219. https://doi.org/10.1029/2011JA016609

Greenwald, R. A., Bristow, W. A., Sofko, G. J., Senior, C., Ceriser, J.-C., \& Szabo, A. (1995). Super Dual Auroral Radar Network radar imaging of dayside high-latitude convection under northward interplanetary magnetic field: Toward resolving the distorted two-cell versus multicell controversy. Journal of Geophysical Research, 100, 19661-19674. https://doi.org/10.1029/95ja01215

Haines, C. A., Owens, M. J., Barnard, L. A., Lockwood, M., \& Ruffenach, A. (2019). The variation of geomagnetic storm duration with intensity. Solar Physics, 294, 154. https://doi.org/10.1007/s11207-019-1546-Z

Hairston, M. R., Heelis, R. A., \& Rich, F. J. (1998). Analysis of the ionospheric cross polar cap potential drop using DMSP data during the National Space Weather Program study period. Journal of Geophysical Research, 103(A11), 26337-26347. https://doi. org/10.1029/97JA03241

Hanson, W. B., Coley, W. R., Heelis, R. A., Maynard, N. C., \& Aggson, T. L. (1993). A Comparison of in situ measurements of and from Dynamics Explorer 2. Journal of Geophysical Research, 98(A12), 21501-21516. https://doi.org/10.1029/93JA01422

Hapgood, M. A., Bowe, G., Lockwood, M., Willis, D. M., \& Tulunay, Y. (1991). Variability of the interplanetary magnetic field at 1 A.U. over 24 years: 1963-1986. Planetary and Space Science, 39, 411-423. https://doi.org/10.1016/0032-0633(91)90003-S

Hapgood, M. A., \& Lockwood, M. (1993). On the voltage and distance across the low-latitude boundary layer. Geophysical Research Letters, 20, 145-148. https://doi.org/10.1029/93GL00063

Holzer, R. E., McPherron, R. L., \& Hardy, D. A. (1986). A quantitative empirical model of the magnetospheric flux transfer process. Journal of Geophysical Research, 91(A3), 3287-3293. https://doi.org/10.1029/JA091iA03p03287

Hones, E. W., Jr., Craven, J. D., Frank, L. A., Evans, D. S., \& Newell, P. T. (1989). The horse-collar aurora: A frequent pattern of the aurora in quiet times. Geophysical Research Letters, 16(1), 37-40. https://doi.org/10.1029/GL016i001p00037

Huang, C.-S., DeJong, A. D., \& Cai, X. (2009). Magnetic flux in the magnetotail and polar cap during sawteeth, isolated substorms, and steady magnetospheric convection events. Journal of Geophysical Research, 114, A07202. https://doi.org/10.1029/2009JA014232

Hubert, B., Milan, S. E., Grocott, A., Block, C., Cowley, S. W. H., \& Gérard, J.-C. (2006). Dayside and nightside reconnection rates inferred from IMAGE FUV and Super Dual Auroral Radar Network data. Journal of Geophysical Research, 111, A03217. https://doi.org/10.1029/2005JA011140

Hubert, B., Palmroth, M., Laitinen, T. V., Janhunen, P., Milan, S. E., Grocott, A., et al. (2006). Compression of the Earth's magnetotail by interplanetary shocks directly drives transient magnetic flux closure. Geophysical Research Letters, 33, L10105. https://doi. org/10.1029/2006GL026008

Imber, S. M., Milan, S. E., \& Lester, M. (2013). Solar cycle variations in polar cap area measured by the superDARN radars. Journal of Geophysical Research: Space Physics, 118(10), 6188-6196. https://doi.org/10.1002/jgra.50509

Karlsson, S. B. P., Opgenoorth, H. J., Eglitis, P., Kauristie, K., Syrjäsuo, M., Pulkkinen, T. I., et al. (2000). Solar wind control of magnetospheric energy content: Substorm quenching and multiple onsets. Journal of Geophysical Research, 105, 5335-5356. https://doi. org/10.1029/1999JA900297

King, J. H., \& Papitashvili, N. E. (2005). Solar wind spatial scales in and comparisons of hourly Wind and ACE plasma and magnetic field data. Journal of Geophysical Research, 110, A02104. https://doi.org/10.1029/2004JA010649

Klimas, A. J., Baker, D. N., Roberts, D. A., Fairfield, D. H., \& Büchner, J. (1992). A nonlinear dynamical analogue model of geomagnetic activity. Journal of Geophysical Research, 97(A8), 12253-12266. https://doi.org/10.1029/92JA00794

Klimas, A. J., Baker, D. N., Vassiliadis, D., \& Roberts, D. A. (1994). Substorm recurrence during steady and variable solar wind driving: Evidence for a normal mode in the unloading dynamics of the magnetosphere. Journal of Geophysical Research, 99, 14855-14861. https:// doi.org/10.1029/94JA01240

Kokubun, S., McPherron, R. L., \& Russell, C. T. (1977). Triggering of substorms by solar wind discontinuities. Journal of Geophysical Research, 82(1), 74-86. https://doi.org/10.1029/ja082i001p00074

Koustov, A. V., Lavoie, D. B., Kouznetsov, A. F., Burchill, J. K., Knudsen, D. J., \& Fiori, R. A. D. (2019). A comparison of cross-track ion drift measured by the Swarm satellites and plasma convection velocity measured by SuperDARN. Journal of Geophysical Research: Space Physics, 124, 4710-4724. https://doi.org/10.1029/2018JA026245

Koustov, A. V., Ullrich, S., Ponomarenko, P. V., Nishitani, N., Marcucci, F. M., \& Bristow, W. A. (2019). Occurrence of F region echoes for the polar cap SuperDARN radars. Earth, Planets and Space, 71, 112. https://doi.org/10.1186/s40623-019-1092-9

Kubota, Y., Nagatsuma, T., Den, M., Tanaka, T., \& Fujita, S. (2017). Polar cap potential saturation during the Bastille Day storm event using global MHD simulation. Journal of Geophysical Research: Space Physics, 122, 4398-4409. https://doi.org/10.1002/2016JA023851

Laundal, K. M., Reistad, J. P., Hatch, S. M., Moretto, T., Ohma, A., Østgaard, N., et al. (2020). Time-scale dependence of solar wind-based regression models of ionospheric electrodynamics. Scientific Reports, 10, 16406. https://doi.org/10.1038/s41598-020-73532-z 
Lee, D.-Y., Lyons, L. R., \& Yumoto, K. (2004). Sawtooth oscillations directly driven by solar wind dynamic pressure enhancements. Journal of Geophysical Research, 109, A04202. https://doi.org/10.1029/2003JA010246

Liu, E., Hu, H., Liu, J., Teng, X., \& Qiao, L. (2019). Predicting SuperDARN cross polar cap potential by applying regression analysis and machine learning. Journal of Atmospheric and Solar-Terrestrial Physics, 193, 105057. https://doi.org/10.1016/j.jastp.2019.105057

Lockwood, M. (1991). On flow reversal boundaries and cross-cap potential in average models of high latitude convection. Planetary and Space Science, 39, 397-409. https://doi.org/10.1016/0032-0633(91)90002-R

Lockwood, M. (2013). Reconstruction and prediction of variations in the open solar magnetic flux and interplanetary conditions. Living Reviews in Solar Physics, 10(4). https://doi.org/10.12942/lrsp-2013-4

Lockwood, M. (2019). Does adding solar wind Poynting flux improve the optimum solar wind-magnetosphere coupling function? Journal of Geophysical Research: Space Physics, 124(7), 5498-5515. https://doi.org/10.1029/2019JA026639

Lockwood, M., Bentley, S., Owens, M. J., Barnard, L. A., Scott, C. J., Watt, C. E., \& Allanson, O. (2019a). The development of a space climatology: 1. Solar-wind magnetosphere coupling as a function of timescale and the effect of data gaps. Space Weather, 17, 133-156. https:// doi.org/10.1029/2018SW001856

Lockwood, M., Bentley, S., Owens, M. J., Barnard, L. A., Scott, C. J., Watt, C. E., et al. (2019b). The development of a space climatology: 2. The distribution of power input into the magnetosphere on a 3-hourly timescale. Space Weather, 17, 157-179. https://doi. org/10.1029/2018SW002016

Lockwood, M., Bentley, S., Owens, M. J., Barnard, L. A., Scott, C. J., Watt, C. E., et al. (2019c). The development of a space climatology: 3. The evolution of distributions of space weather parameters with timescale. Space Weather, 17, 180-209. https://doi. org/10.1029/2018SW002017

Lockwood, M., Chambodut, A., Barnard, L. A., Owens, M. J., Clarke, E., \& Mendel, V. (2018). A homogeneous aa index: 1. Secular variation. Journal of Space Weather and Space Climate, 8, A53. https://doi.org/10.1051/swsc/2018038

Lockwood, M., \& Cowley, S. W. H. (1992). Ionospheric convection and the substorm cycle. In C. Mattock (Ed.), Substorms 1 (pp. 99-109). Proceedings of the First International Conference on Substorms, ICS-1, European Space Agency Publications.

Lockwood, M., Cowley, S. W. H., \& Freeman, M. P. (1990). The excitation of plasma convection in the high latitude ionosphere. Journal of Geophysical Research, 95, 7961-7971. https://doi.org/10.1029/JA095iA06p07961

Lockwood, M., Cowley, S. W. H., Todd, H., Willis, D. M., \& Clauer, C. R. (1988). Ion flows and heating at a contracting polar cap boundary. Planetary and Space Science, 36, 1229-1253. https://doi.org/10.1016/0032-0633(88)90076-1

Lockwood, M., Denig, W. F., Farmer, A. D., Davda, V. N., Cowley, S. W. H., \& Lühr, H. (1993). Ionospheric signatures of pulsed magnetic reconnection at the Earth's magnetopause. Nature, 361(6411), 424-428. https://doi.org/10.1038/361424a0

Lockwood, M., Finch, I. D., Chambodut, A., Barnard, L. A., Owens, M. J., \& Clarke, E. (2018). A homogeneous aa index: 2. Hemispheric asymmetries and the equinoctial variation. Journal of Space Weather and Space Climate, 8, A58. https://doi.org/10.1051/swsc/2018044

Lockwood, M., Haines, C. A., Barnard, L. A., Owens, J., Scott, C. J., Chambodut, A., \& McWilliams, K. A. (2021). Semi-annual, annual and Universal Time variations in the magnetosphere and in geomagnetic activity: 4. Polar Cap motions and origins of the Universal Time effect. Journal of Space Weather and Space Climate, 11, 15. https://doi.org/10.1051/swsc/2020077

Lockwood, M., Hairston, M. R., Finch, I. D., \& Rouillard, A. P. (2009). Transpolar voltage and polar cap flux during the substorm cycle and steady convection events. Journal of Geophysical Research, 114, A01210. https://doi.org/10.1029/2008JA013697

Lockwood, M., \& Hapgood, M. A. (1997). How the magnetopause transition parameter works. Geophysical Research Letters, 24, 373-376. https://doi.org/10.1029/97GL00120

Lockwood, M., Lanchester, B., Morley, S. K., Milan, S. E., Lester, M., \& Frey, H. U. (2006). Modelling the observed proton aurora and ionospheric convection responses to changes in the IMF field clock angle: 2 . The persistence of ionospheric convection. Journal of Geophysical Research, 111, A02306. https://doi.org/10.1029/2003JA010307

Lockwood, M., Lanchester, B. S., Frey, H., Throp, K., Morley, S., Milan, S. E., \& Lester, M. E. (2003). IMF control of Cusp proton emission intensity and dayside convection: Implications for component and anti-parallel reconnection. Annales Geophysicae, 21, 955-982. https://doi.org/10.5194/angeo-21-955-2003

Lockwood, M., McWilliams, K. A., Owens, M. J., Barnard, L. A., Watt, C. E., Scott, C. J., et al. (2020). Semi-annual, annual and Universal Time variations in the magnetosphere and in geomagnetic activity: 2 . Response to solar wind power input and relationships with solar wind dynamic pressure and magnetospheric flux transport. Journal of Space Weather and Space Climate, 10, 30. https://doi.org/10.1051/ swsc/2020033

Lockwood, M., \& Moen, J. (1999). Reconfiguration and closure of lobe flux by reconnection during northward IMF: Evidence for signatures in cusp/cleft auroral emissions. Annales Geophysicae, 17, 996-1011. https://doi.org/10.1007/s00585-999-0996-2

Lockwood, M., \& Morley, S. E. (2004). A numerical model of the ionospheric signatures of time-varying magnetic reconnection: I. Ionospheric convection. Annales Geophysicae, 22, 73-91. https://doi.org/10.5194/angeo-22-73-2004

Lockwood, M., Owens, M. J., Barnard, L. A., Bentley, S., Scott, C. J., \& Watt, C. E. (2016). On the origins and timescales of geoeffective IMF. Space Weather, 14, 406-432. https://doi.org/10.1002/2016SW001375

Lockwood, M., Owens, M. J., Barnard, L. A., Scott, C. J., \& Watt, C. E. (2017). Space Climate and Space Weather over the past 400 years: 1. The Power input to the Magnetosphere. Journal of Space Weather and Space Climate, 7, A25. https://doi.org/10.1051/swsc/2017019

Lockwood, M., Owens, M. J., Barnard, L. A., Watt, C. E., Scott, C. J., Coxon, J. C., \& McWilliams, K. A. (2020). Semi-annual, annual and Universal Time variations in the magnetosphere and in geomagnetic activity: 3. Modelling. Journal of Space Weather and Space Climate, 10, 61. https://doi.org/10.1051/swsc/2020062

Lockwood, M., van Eyken, A. P., Bromage, B. J. I., Willis, D. M., \& Cowley, S. W. H. (1986). Eastward propagation of a plasma convection enhancement following a southward turning of the interplanetary magnetic field. Geophysical Research Letters, 13, 72-75. https://doi. org/10.1029/GL013i001p00072

Lopez, R. E., Lyon, J. G., Wiltberger, M. J., \& Goodrich, C. C. (2001). Comparison of global MHD simulation results with actual storm and substorm events. Advances in Space Research, 28(12), 1701-1706. https://doi.org/10.1016/S0273-1177(01)00535-X

Lopez, R. E., Wiltberger, M., Lyon, J. G., Goodrich, C. C., \& Papadopoulos, K. (1999). MHD simulations of the response of high-latitude potential patterns and polar cap boundaries to sudden southward turnings of the interplanetary magnetic field. Geophysical Research Letters, 26(7), 967-970. https://doi.org/10.1029/1999GL900113

Lühr, H., Lockwood, M., Sandholt, P. A., Hansen, T. L., \& Moretto, T. (1996). Multi-instrument ground-based observations of a Travelling Convection Vortex event. Annales Geophysicae, 14, 162-181. https://doi.org/10.1007/s00585-996-0162-z

Lukianova, R. (2003). Magnetospheric response to sudden changes in solar wind dynamic pressure inferred from polar cap index. Journal of Geophysical Research, 108(A12), 1428. https://doi.org/10.1029/2002JA009790 
Mayaud, P.-N. (1980). Derivation, meaning and use of geomagnetic indices (Geophysical Monograph, Vol. 22). American Geophysical Union. https://doi.org/10.1029/GM022

McPherron, R. L. (2020). Early studies in solar wind coupling and substorms. Journal of Geophysical Research: Space Physics, 125, e2019JA027615. https://doi.org/10.1029/2019JA027615

McPherron, R. L., Baker, D. N., Bargatze, L. F., Clauer, C. R., \& Holzer, R. E. (1998). IMF control of geomagnetic activity. Advances in Space Research, 8(9-10), 71-86. https://doi.org/10.1016/0273-1177(88)90114-7

McWilliams, K. A., Pfeifer, J. B., \& McPherron, R. L. (2008). Steady magnetospheric convection selection criteria: Implications of global SuperDARN convection measurements. Geophysical Research Letters, 35, L09102. https://doi.org/10.1029/2008GL033671

McWilliams, K. A., Yeoman, T. K., \& Cowley, S. W. H. (2000). Two-dimensional electric field measurements in the ionospheric footprint of a flux transfer event. Annales Geophysicae, 18(12), 1584-1598. https://doi.org/10.1007/s00585-001-1584-2

Milan, S. E. (2004). Dayside and nightside contributions to the cross polar cap potential: Placing an upper limit on a viscous-like interaction. Annales Geophysicae, 22, 3771-3777. https://doi.org/10.5194/angeo-22-3771-2004

Milan, S. E., Carter, J. A., Bower, G. E., Imber, S. M., Paxton, L. J., Anderson, B. J., et al. (2020). Dual-lobe reconnection and horse-collar auroras. Journal of Geophysical Research: Space Physics, 125, e2020JA028567. https://doi.org/10.1029/2020JA028567

Milan, S. E., Carter, J. A., Sangha, H., Bower, G. E., \& Anderson, B. J. (2021). Magnetospheric flux throughput in the Dungey cycle: Identification of convection state during 2010. Journal of Geophysical Research: Space Physics, 126, e2020JA028437. https://doi. org/10.1029/2020JA028437

Milan, S. E., Gosling, J. S., \& Hubert, B. (2012). Relationship between interplanetary parameters and the magnetopause reconnection rate quantified from observations of the expanding polar cap. Journal of Geophysical Research, 117, A03226. https://doi. org/10.1029/2011JA017082

Milan, S. E., Hutchinson, J., Boakes, P. D., \& Hubert, B. (2009). Influences on the radius of the auroral oval. Annales Geophysicae, 21(5), 1121-1140. https://doi.org/10.5194/angeo-21-1121-2003

Milan, S. E., Lester, M., Cowley, S. W. H., Oksavik, K., Brittnacher, M., Greenwald, R. A., et al. (2003). Variations in the polar cap area during two substorm cycles. Annales Geophysicae, 21(5), 1121-1140. https://doi.org/10.5194/angeo-21-1121-2003

Mishin, V., \& Karavaev, Y. (2017). Saturation of the magnetosphere during superstorms: New results from the magnetogram inversion technique. Solar-Terrestrial Physics, 3(3), 28-36. https://doi.org/10.12737/stp-33201704

Morley, S. E., \& Lockwood, M. (2005). A numerical model of the ionospheric signatures of time-varying magnetic reconnection: II. Measuring expansions in the ionospheric flow response. Annales Geophysicae, 23, 2501-2510. https://doi.org/10.5194/angeo-23-2501-2005

Mozer, F. S. (1984). Electric field evidence on the viscous interaction at the magnetopause. Geophysical Research Letters, 11, 135-138. https://doi.org/10.1029/GL011i002p00135

Mozer, F. S., Hayakawa, H., Kokubun, S., Nakamura, M., Okada, T., Yamamoto, T., \& Tsuruda, K. (1994). The morningside low-latitude boundary layer as determined from electric and magnetic field measurements on Geotail. Geophysical Research Letters, 21(25), 29832986. https://doi.org/10.1029/94GL01296

Newell, P. T., Burke, W. J., Sanchez, E. R., Greenspan, M. E., \& Clauer, C. R. (1991). The low-latitude boundary layer and the boundary plasma sheet at low altitude: Prenoon precipitation regions and convection reversal boundaries. Journal of Geophysical Research, 96, 21013-21023. https://doi.org/10.1029/91ja01818

Nishida, A. (1968a). Coherence of geomagnetic DP 2 fluctuations with interplanetary magnetic variations. Journal of Geophysical Research, 73(17), 5549-5559. https://doi.org/10.1029/JA073i017p05549

Nishida, A. (1968b). Geomagnetic DP 2 fluctuations and associated magnetospheric phenomena. Journal of Geophysical Research, 73(5), 1795-1803. https://doi.org/10.1029/JA073i005p01795

Ober, D. M., Wilson, G. R., Maynard, N. C., Burke, W. J., \& Siebert, K. D. (2006). MHD simulation of the transpolar potential after a solar-wind density pulse. Geophysical Research Letters, 539(33), L04106. https://doi.org/10.1029/2005GL024655

Palmroth, M., Pulkkinen, T. I., Janhunen, P., McComas, D. J., Smith, C. W., \& Koskinen, H. E. J. (2004). Role of solar wind dynamic pressure in driving ionospheric Joule heating. Journal of Geophysical Research, 109, A11302. https://doi.org/10.1029/2004JA010529

Pitout, F., Newell, P. T., \& Buchert, S. C. (2002). Simultaneous high-and low-latitude reconnection: ESR and DMSP observations. Annales Geophysicae, 20(9), 1311-1320. https://doi.org/10.5194/angeo-20-1311-2002

Provan, G., Yeoman, T. K., Milan, S. E., Ruohoniemi, J. M., \& Barnes, R. (2002). An assessment of the "map-potential” and "beam-swinging" techniques for measuring the ionospheric convection pattern using data from the SuperDARN radars. Annales Geophysicae, 20, 191-202. https://doi.org/10.5194/angeo-20-191-2002

Reiff, P. H., Spiro, R. W., \& Hill, T. W. (1981). Dependence of polar cap potential drop on interplanetary parameters. Journal of Geophysical Research, 86(A9), 7639-7648. https://doi.org/10.1029/JA086iA09p07639

Ruohoniemi, J. M., \& Baker, K. B. (1998). Large-scale imaging of high-latitude convection with Super Dual Auroral Radar Network HF radar observations. Journal of Geophysical Research, 103, 20797-20811. https://doi.org/10.1029/98ja01288

Saunders, M. A., Freeman, M. P., Southwood, D. J., Cowley, S. W. H., Lockwood, M., Samson, J. C., et al. (1992). Dayside ionospheric convection changes in response to long period IMF oscillations: Determination of the ionospheric phase velocity. Journal of Geophysical Research, 97, 19373-19380. https://doi.org/10.1029/92JA01383

Schieldge, J. P., \& Siscoe, G. L. (1970). A correlation of the occurrence of simultaneous sudden magnetospheric compressions and geomagnetic bay onsets with selected geophysical indices. Journal of Atmospheric and Terrestrial Physics, 32(11), 1819-1830. https://doi. org/10.1016/0021-9169(70)90139-x

Scurry, L., \& Russell, C. T. (1991). Proxy studies of energy transfer to the magnetosphere. Journal of Geophysical Research, 96(A6), 95419548. https://doi.org/10.1029/91JA00569

Shepherd, S. G., \& Ruohoniemi, J. M. (2000). Electrostatic potential patterns in the high-latitude ionosphere constrained by SuperDARN measurements. Journal of Geophysical Research, 105, 23005-23014. https://doi.org/10.1029/2000ja000171

Siscoe, G. L., \& Huang, T. S. (1985). Polar cap inflation and deflation. Journal of Geophysical Research, 90(A1), 543-547. https://doi. org/10.1029/JA090iA01p00543

Stauning, P., \& Troshichev, O. A. (2008). Polar cap convection and PC index during sudden changes in solar wind dynamic pressure. Journal of Geophysical Research, 113, A08227. https://doi.org/10.1029/2007JA012783

Sundberg, K. Å. T., Blomberg, L. G., \& Cumnock, J. A. (2008). Statistical analysis of the sources of the cross-polar potential for southward IMF, based on particle precipitation characteristics. Geophysical Research Letters, 35, L08103. https://doi.org/10.1029/2008GL033383

Throp, K., Lockwood, M., Lanchester, B. S., Morley, S. K., \& Frey, H. U. (2005). Modeling the observed proton aurora and ionospheric convection responses to changes in the IMF clock angle: 1. Persistence of cusp proton aurora. Journal of Geophysical Research, 110, A12311. https://doi.org/10.1029/2003JA010306 
Todd, H., Cowley, S. W. H., Etemadi, A., Bromage, B. J. I., Lockwood, M., Willis, D. M., \& Lühr, H. (1988). Flow in the high-latitude ionosphere: Measurements at 15-second resolution made using the EISCAT "POLAR" experiment. Journal of Atmospheric and Terrestrial Physics, 50, 423-446. https://doi.org/10.1016/0021-9169(88)90026-8

Weigel, R. S. (2007). Solar wind time history contribution to the day-of-year variation in geomagnetic activity. Journal of Geophysical Research, 112, A10207. https://doi.org/10.1029/2007JA012324

Weimer, D. R., Maynard, N. C., Burke, W. J., \& Liebrecht, C. (1990). Polar cap potentials and the auroral electrojet indices. Planetary and Space Science, 38(9), 1207-1222. https://doi.org/10.1016/0032-0633(90)90028-o

Wilder, F. D., Clauer, C. R., \& Baker, J. B. H. (2008). Reverse convection potential saturation during northward IMF. Geophysical Research Letters, 35, L12103. https://doi.org/10.1029/2008GL034040

Wilder, F. D., Clauer, C. R., Baker, J. B. H., Cousins, E. P., \& Hairston, M. R. (2011). The nonlinear response of the polar cap potential under southward IMF: A statistical view. Journal of Geophysical Research, 116, A12229. https://doi.org/10.1029/2011JA016924

Wygant, J. R., Torbert, R. B., \& Mozer, F. S. (1983). Comparison of S3-3 polar cap potential drops with the interplanetary magnetic field and models of magnetopause reconnection. Journal of Geophysical Research, 88(A7), 5727-5735. https://doi.org/10.1029/JA088iA07p05727

Xu, L., Koustov, A. V., Xu, J. S., Drayton, R. A., \& Huo, L. (2007). A 2-D comparison of ionospheric convection derived from SuperDARN and DMSP measurements. Advances in Space Research, 42(7), 1259-1266. https://doi.org/10.1016/j.asr.2007.06.044

$\mathrm{Xu}, \mathrm{L} ., \mathrm{Xu}, \mathrm{J} ., \mathrm{Al} \mathrm{xandre,} \mathrm{K.,} \mathrm{Papitashvili,} \mathrm{V.,} \mathrm{\&} \mathrm{Rich,} \mathrm{F.} \mathrm{(2007).} \mathrm{A} \mathrm{comparison} \mathrm{of} \mathrm{SuperDARN-derived} \mathrm{plasma} \mathrm{convection} \mathrm{and} \mathrm{DMSP} \mathrm{ion}$ drift measurements. Wuhan University Journal of Natural Sciences, 12, 279-283. https://doi.org/10.1007/s11859-006-0024-2

Yue, C., Zong, Q. G., Zhang, H., Wang, Y. F., Yuan, C. J., Pu, Z. Y., et al. (2010). Geomagnetic activity triggered by interplanetary shocks. Journal of Geophysical Research, 115, A00I05. https://doi.org/10.1029/2010JA015356 